Electrophysiological Profile of Differentiating Human Central Canal Ependymal StemProgenitor Cells

A thesis presented to the Faculty of Graduate and Postdoctoral Affairs in partial fulfillment of the requirements

for the degree of

Master of Science

In

Neuroscience

Carleton University

Ottawa, Ontario

(C) 2018

Kyle Malone 


\section{Electrophysiological Profile of Differentiating Human Central Canal Ependymal Stem- Progenitor Cells}

Following spinal cord injury (SCI), current treatments look to halt the spread of tissue damage to minimize pain, with limited effectiveness. Unfortunately, there is no widely used approach for promoting re-growth across the lesion site, a necessity for functional recovery. To that end, stem cell transplant and niche manipulation therapies are a promising tool for repairing damage from SCI and other neurodegenerative conditions. As most stem cell studies are based exclusively on animal models, we aimed to address several gaps in understanding that are fundamental for potential translation to humans. Since immunocytochemistry alone cannot adequately determine whether stem cells have differentiated into mature neurons, we used patchclamp electrophysiology to assess the passive and active electrical properties of stem cells from the central canal of the spinal cord throughout the in vitro differentiation process. Rat ependymal-stem progenitor cells (epSPCs) differentiate towards a majority astrocytic fate under intrinsic differentiation conditions in vitro. Human epSPCs, on the other hand, differentiate towards a majority neuronal fate. Electrophysiological recordings of these cells in intrinsic FBScontaining differentiation media and under BDNF-, GDNF- and RA-guided differentiation show no action potential firing from two to ten weeks in vitro. Passive membrane properties fail to reach that of typical mature neurons within this time frame. Surprisingly, the vast majority of cells showed voltage-dependent spontaneous synaptic currents with reversal near $0 \mathrm{mV}$, outward rectification, and decay kinetics that are consistent with excitatory glutamatergic responses. Further studies investigating the necessary timeline and the most effective differentiation media required for development of active membrane properties are needed, as is identification of the receptor subtypes responsible for the observed synaptic currents. This will help inform future transplant and stem cell niche manipulation strategies for the treatment of human neurological disorders. 


\section{Acknowledgements}

I would like to thank Dr. Michael Hildebrand for the opportunity to study and be a part of the research conducted in his lab. His enthusiasm for the research, unending patience in guiding my work, and thoroughness in editing my writing made all of this possible. His seemingly infinite stores of positivity and encouragement turned near-catastrophic circumstances into tremendous opportunities for growth and collaboration.

I would like to thank Carleton University for their exemplary handling of the departmental move. Without it my project would never have existed in its current form.

Most importantly, I would like to thank Sufi Baba Budan, the first person to smuggle coffee out of the Middle East in 1670 by strapping beans to his chest, setting off an explosion in trade and ultimately allowing me the mental faculties to get any work done on little to no sleep. Thank you Sufi you brilliant sneak.

Thank you. 


\section{Table of Contents}

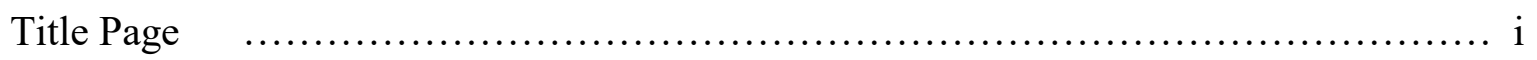

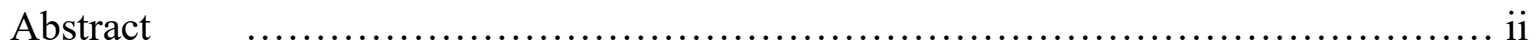

Acknowledgements ............................................................... ii

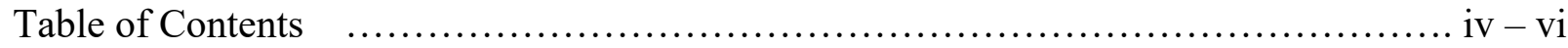

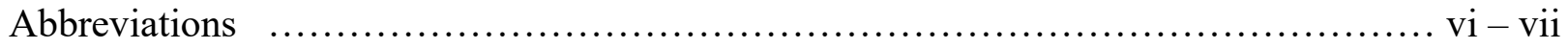

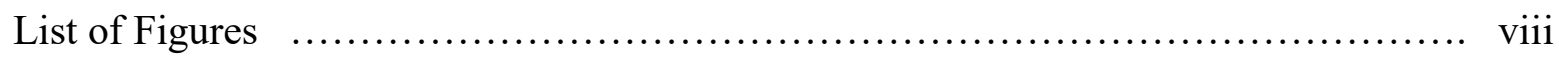

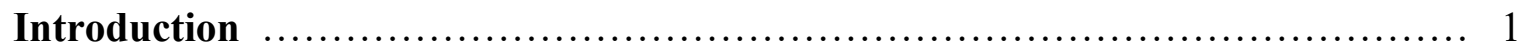

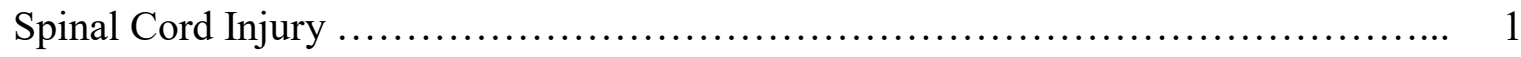

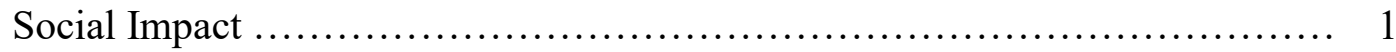

Basic Pathology ..................................................... 1

Current Treatments .................................................... 4

Ependymal Cells ............................................................... 5

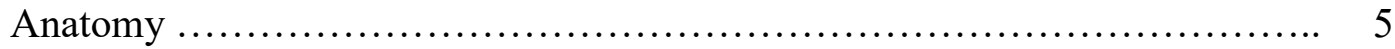

Stem Cell Properties ...................................................... 8

Rodents and Mammals ................................................. 10

Humans ............................................................ 14

Exogenous Factors .................................................. 16

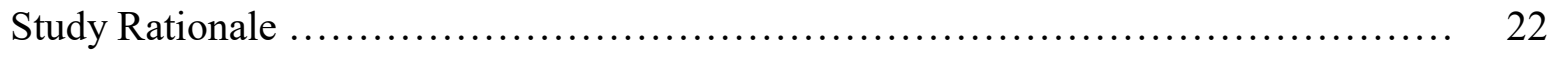

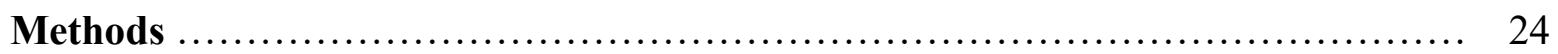

Tissue Collection And Isolation ............................................... 24

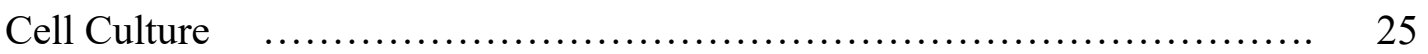

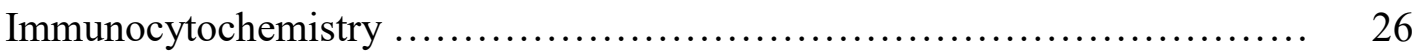

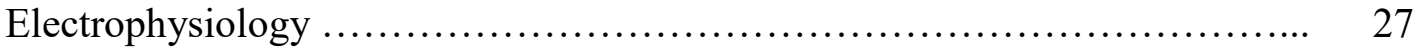

Analysis ............................................................... 29

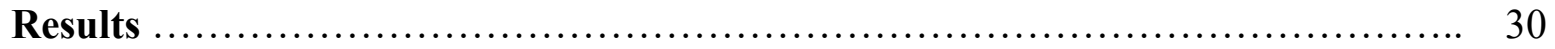

Differentiation ........................................................ 30

Current Clamp ......................................................... 31

Voltage Clamp ........................................................ 39

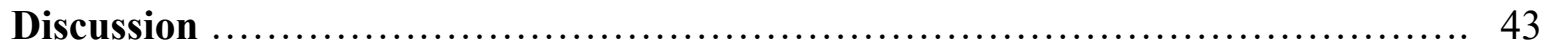

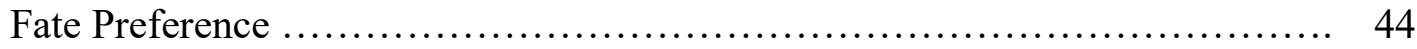

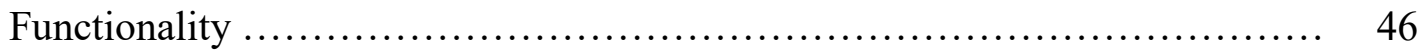

Passive Properties ....................................................... 49 


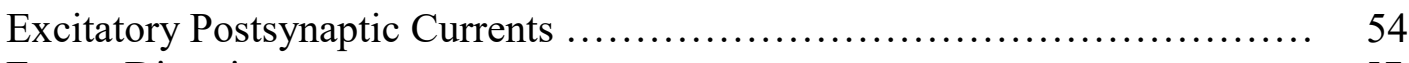

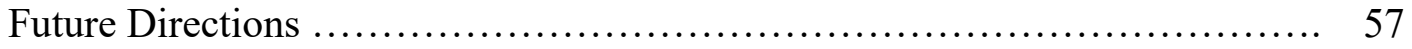

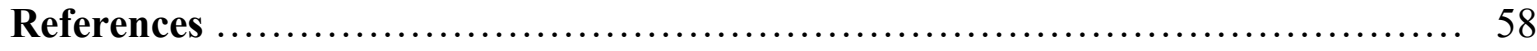




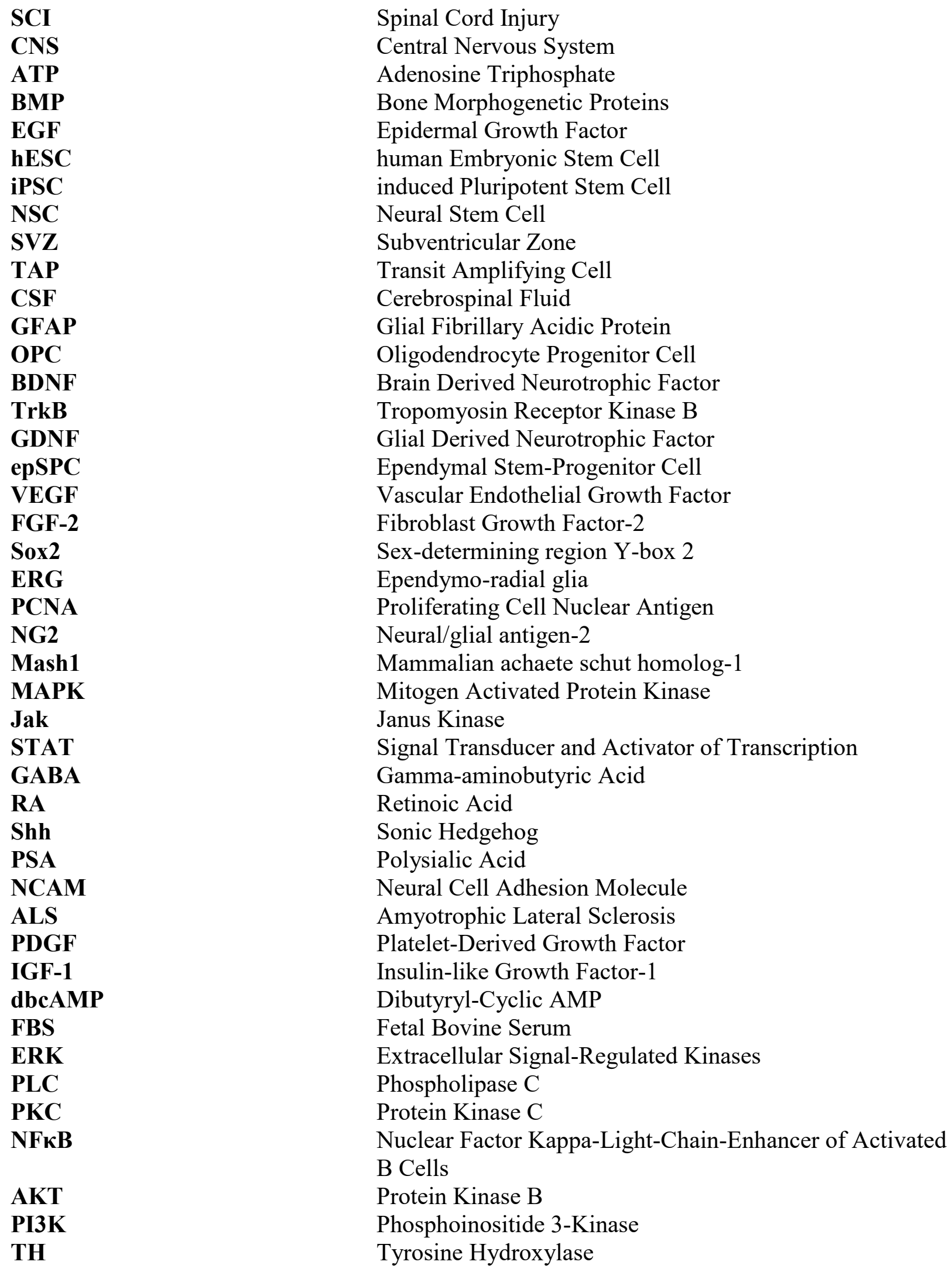

SCI

CNS

ATP

BMP

EGF

hESC

iPSC

NSC

SVZ

TAP

CSF

GFAP

OPC

BDNF

TrkB

GDNF

epSPC

VEGF

FGF-2

Sox 2

ERG

PCNA

NG2

Mash1

MAPK

Jak

STAT

GABA

RA

Shh

PSA

NCAM

ALS

PDGF

IGF-1

dbcAMP

FBS

ERK

PLC

PKC

NFкB

AKT

PI3K

TH

Spinal Cord Injury

Central Nervous System

Adenosine Triphosphate

Bone Morphogenetic Proteins

Epidermal Growth Factor

human Embryonic Stem Cell

induced Pluripotent Stem Cell

Neural Stem Cell

Subventricular Zone

Transit Amplifying Cell

Cerebrospinal Fluid

Glial Fibrillary Acidic Protein

Oligodendrocyte Progenitor Cell

Brain Derived Neurotrophic Factor

Tropomyosin Receptor Kinase B

Glial Derived Neurotrophic Factor

Ependymal Stem-Progenitor Cell

Vascular Endothelial Growth Factor

Fibroblast Growth Factor-2

Sex-determining region Y-box 2

Ependymo-radial glia

Proliferating Cell Nuclear Antigen

Neural/glial antigen-2

Mammalian achaete schut homolog-1

Mitogen Activated Protein Kinase

Janus Kinase

Signal Transducer and Activator of Transcription

Gamma-aminobutyric Acid

Retinoic Acid

Sonic Hedgehog

Polysialic Acid

Neural Cell Adhesion Molecule

Amyotrophic Lateral Sclerosis

Platelet-Derived Growth Factor

Insulin-like Growth Factor-1

Dibutyryl-Cyclic AMP

Fetal Bovine Serum

Extracellular Signal-Regulated Kinases

Phospholipase C

Protein Kinase C

Nuclear Factor Kappa-Light-Chain-Enhancer of Activated

B Cells

Protein Kinase B

Phosphoinositide 3-Kinase

Tyrosine Hydroxylase

\section{Abbreviations}


LMX1A

PTX3

SFM

Cm

Rn

RMP

TIC

PDL

TGF

cAMP

NT3

NGF
LIM homeobox transcription factor 1 alpha

Pentraxin-related Protein 3

Serum Free Media

Capacitance

Input Resistance

Resting Membrane Potential

Time In Culture

Poly-D-Lysine

Transforming Growth Factor

cyclic Adenosine Monophosphate

Neurotrophin 3

Nerve Growth Factor 
Figure 1: Differentiated human epSPCs preferentially express $\beta$ III-tubulin 31

Figure 2: Differentiating epSPCs cultured on matrigel-coated coverslips express 32 neuronal markers

Figure 3: Differentiating epSPCs expressing neuronal markers do not fire action potentials

Figure 4: Time in culture has no significant effect on passive membrane properties

Figure 5: FBS produces cells with more hyperpolarized membranes

Figure 6: Cells lacking action potential firing display synaptic responses

Figure 7: Time in culture decreases decay constant at positive holding potentials with no effect on amplitude 


\subsection{Spinal Cord Injury}

\subsection{Societal Impact}

Acute spinal cord injury (SCI) has a worldwide incidence of $15-40$ cases per million ${ }^{1}$, with 130,000 new cases yearly ${ }^{2,3}$. Falls, violent crime, sports and motor vehicle accidents are the most common causes, with patients typically males between 15 and 25 years old ${ }^{1,4-8}$. Individuals above 60 years old represent the second most prevalent age group, with increased vulnerability due to age-related bone changes ${ }^{9}$. The cervical spine is the most frequently affected and neurologically devastating region, representing up to $63 \%$ of all SCI cases in the United States ${ }^{1,5}$. Cervical SCI results in tetraplegia, with injuries in lower regions resulting in paraplegia ${ }^{5}$. Lifetime costs depend on age of onset, but typically range from 1-4.5 million dollars US ${ }^{1,4,10,11}$. Neurological deficits present immediately ${ }^{1,4}$ and include motor, sensory and autonomic dysfunction from which more than half of patients do not recover ${ }^{5,6}$. As such, it is necessary to explore new, more effective treatments.

\subsection{Basic Pathology}

The mammalian central nervous system (CNS) has little self-repair capacity, with recovery from CNS injuries difficult and often irreversible. SCI occurs in two phases. The primary injury phase is the initial mechanical injury to the spinal cord, with disruption of blood vessels, cell membranes and axons ${ }^{11}$. Injuries can be compression, laceration, contusion or vascular insults ${ }^{9}$. In humans, the most common clinical presentation is fracture dislocation, with vertebrae compression affecting dorsal areas of the spinal $\operatorname{cord}^{11}$. Complete transection injuries are extremely rare, with some demyelinated axons usually left crossing the injury site. These present a target for remyelination and regenerative therapies ${ }^{1,4}$. Most primary SCIs are spread over multiple spinal segments, and involve meningeal laceration and subarachnoid hemorrhage ${ }^{12}$. 
Clinically, SCI presents as either complete (no motor or sensory function) or incomplete (some preserved function), and as either central cord, anterior cord, or posterior cord syndromes based upon the affected spinal cord $\operatorname{area}^{6}$. There is immediate damage to neural tissue and vasculature, leading to mechanical and ischemic-induced necrosis. Plasma membrane permeability increases and excitatory neurotransmitters accumulate. Injured neurons fire frequent action potentials over the next 24 hours, resulting in shifts in intracellular and extracellular ionic balances that contribute to spinal shock ${ }^{2,8,9}$.

The secondary injury cascade follows, with excitotoxicity, inflammation, production of free radicals, swelling, ischemia, and extensive apoptotic cell death ${ }^{1,4,8}$. Lesion size increases ${ }^{8}$ to several time its initial size ${ }^{2}$, and there is a progressive reduction in blood flow to spinal cord white and grey matter hours after SCI, with consequent hypoxia leading to further free-radical production and lipid peroxidation ${ }^{12}$. The secondary injury occurs in three temporally defined phases. The acute phase is characterized by excitotoxicity, inflammation induced apoptosis and axon damage, necrosis, ionic dysregulation, decreased ATP, extensive free-radical production, lipid peroxidation, blood vessel damage, hemorrhage, and ischemia. Following this, the intermediate phase begins. A significant buildup of neurite growth-inhibitory factors limits axon regrowth, and the astrocytic scar forms. Finally, 6 months post-injury the chronic phase begins, continuing throughout life. This phase is notable for lesion stabilization, white and gray matter death, deposition of connective tissue, further scar formation, cyst formation and Wallerian axon degeneration, with removal of severed axons and their cell bodies ${ }^{1,2,11}$. In mammals, demyelination, axon damage, and death of astrocytes, oligodendrocytes, motor neurons and interneurons causes irreversible loss of function distal to the injury site ${ }^{11,13}$. Inflammation 
persists indefinitely across multiple species ${ }^{14}$. A delayed myelopathy is often seen $5-10$ years post-injury, with cyst formation and hemorrhagic necrosis in the center of the cord ${ }^{12}$.

The glial scar is composed mainly of reactive astrocytes, with varying levels of extracellular matrix proteins (especially chondroitin sulfate proteoglycans, which play inhibitory roles in axon growth during neuronal pattern formation), glial progenitors, Schwann cells, fibroblasts and microglia ${ }^{3,15}$. This scar appears and matures over 3 weeks following injury in rodents and over 4-6 months in humans ${ }^{7}$. The scar environment includes a build-up of molecules inhibitory towards nerve growth with a concurrent shortage of nerve growth stimulation factors ${ }^{7}$, acting as both a physical and chemical barrier to regrowth. Myelin-associated growth inhibitors further contribute to this inhibition ${ }^{16}$. Bone morphogenetic proteins (BMPs), matrix metalloproteins, epidermal growth factor (EGF), ephrins, and cytoskeletal filaments are increased following injury and have roles in scar formation, maintenance and prevention of growth $^{16}$.

The injury site involves the glial scar at the core, surrounded by the glial limitans, a fibrotic scar, and a cavity of reactive astrocytes and ependymal cells ${ }^{16}$. Removal of the glial scar in SCI mouse models results in increased lesion size and even poorer functional outcomes ${ }^{7}$, illustrating at least some beneficial effect early on. However, the chronic phase eventually leads to neurological impairments of axonal tracts in both retrograde and orthograde directions, and can affect brain regions ${ }^{3,15}$. Muscle wasting, chronic pain, pressure sores and urinary infections are common chronic symptoms, and the glial scar has been seen even 30 years post-injury ${ }^{7}$. 


\subsection{Current Treatments}

No effective treatments for neurological improvement and neuronal regeneration after SCI exist at present ${ }^{1,3,10,15}$. The current accepted approach to treating SCI is surgery, with the goal of decompression (reducing swelling), stabilization, and/or treatment of concurrent nonspinal injuries. Approximately $70 \%$ of SCI patients receive surgery within 1 week of injury ${ }^{4,15}$. The mainstay pharmacological intervention for SCI is methylprednisone, a corticosteroid prescribed as a free-radical scavenger and anti-inflammatory with roles in blood-spinal cord barrier maintenance and spinal cord blood flow enhancement ${ }^{15}$. Neither of these promote regeneration, however. To that end, there are extensive experimental approaches aimed at achieving better functional outcomes.

Experimental treatments look to reverse the balance of pro- and anti-regenerative signaling following SCI. Unfortunately, none of these have passed clinical trials to become widely accepted treatments ${ }^{1,3,8,15-18}$. Animal models have shown that only about $10 \%$ of spinal axons are required for return of mobility ${ }^{12,15}$. Stem cell-based regeneration via replacement of lost tissue is a major area in SCI treatment research, focusing on human embryonic stem cells (hESCs), induced pluripotent stem cells (iPSCs), and neural stem cells (NSCs) ${ }^{19}$. Regardless of strategy, understanding the signaling factors involved in the stem cell niche and the properties of differentiated progeny is a key step towards developing effective therapies. ESCs and iPSCs are pluripotent, meaning they can differentiate into nearly all cell types in the body. iPSCs are reprogrammed from mature somatic cells into a pluripotent state. NSCs are multipotent, meaning they can differentiate into cell types of a certain lineage only; in this case, cells of the nervous system $^{19}$. 
In adults, stem cells typically function throughout life in maintaining and regenerating tissues by replenishing depleted cell numbers following injury. Their proliferation, differentiation and survival are mediated by the niche of surrounding cells and signaling molecules ${ }^{20}$. In fitting with the idea that most mammalian CNS neurogenesis ceases shortly after birth $^{21}$, and that it has limited regenerative capacity, only two principal pools of NSCs have been described: the hippocampal dentate gyrus, with roles in memory formation; and the subventricular zone (SVZ), replacing neurons in the olfactory epithelium ${ }^{22}$. The most well characterized CNS stem cell niche is the SVZ, which consists of dormant ependymal cells lining the lateral ventricles, and a highly proliferative subependymal region consisting of blood vessels, neuroblasts, tanycytes, microglia, astrocytes, and pluripotent transit amplifying cells (TAPs), which divide a set number of times before differentiating ${ }^{20,23}$. The astrocytes in this region are the source of SVZ neural stem cell potential, producing TAPs and neuroblasts which migrate to the olfactory bulb and replace lost interneurons ${ }^{20}$.

A third population of NSCs has recently been described in the central canal, with constituent ependymal cells displaying stem cell properties following injury or after induction in $v_{i t r o}{ }^{22}$. To that end, the ependymal cells of the spinal cord central canal represent an ideally placed stem cell niche for manipulation following SCI.

\subsection{Ependymal Cells}

\subsection{Anatomy}

In adult mice, ependymal cells lining the lateral ventricles are postmitotic and rarely divide $^{24}$. Ependymal cells lining the ventricles of the brain and those making up the spinal cord central canal originate from the neuroepithelium ${ }^{25-27}$, beginning to proliferate shortly after 
formation of the neural plate ${ }^{28}$. In adults, they occupy the region of the spinal cord where the central canal once was. For most mammalian species, the central canal is an uninterrupted monolayer of columnar ependymal cells ${ }^{28}$. In humans, this develops over time from a pseudostratified epithelium ${ }^{29}$. The central canal is a cerebrospinal fluid (CSF) cavity running from the conus medullaris in the lumbar spine (where it terminates in a widened structure called the ventriculus terminalis of Krause $)^{30}$ to the fourth ventricle ${ }^{31}$. It is formed during neurulation inside the developing neural tube. Fusion of the neural folds results in openings at either end, opening the neural canal to the amniotic cavity ${ }^{32}$. The rostral and caudal ends close off on embryonic days 25 and 27, respectively, whereby the neural canal becomes the ventricular system. Further neural tube thickening decreases the size of the neural canal until the central canal of the spinal cord is minute ${ }^{33}$. A single layer of columnar ependymal cells comprise the wall of the neural tube, and during development give rise to all neural tissue in the spinal cord through neuroblast and glioblast formation ${ }^{32}$.

In humans, these cells show cuboidal, radial, tanycytic ${ }^{23}$, squamous $^{28}$ and cylindrical morphology with substantial mitochondria and pale cytoplasms ${ }^{34}$. Intermediate phenotypes are abundant, but cuboidal and tanycytic are the most common ${ }^{35}$. Cuboidal ependymal cells have 1-3 cilia $^{35,36}$ and are connected via gap junctions ${ }^{37}$. The dorsal and ventral poles of the central canal also contain ependymal cells morphologically analogous to radial glia in the brain. They contact the pia mater and ventricular surface with long basal processes and shorter apical processes, respectively ${ }^{11}$, along the dorsoventral axis ${ }^{36}$. The central canal has long been thought to be completely eliminated by adulthood ${ }^{38,39}$ through a gradual closing off of the CSF-containing tube $^{40}$ via occlusion by ependymal cell debris ${ }^{30,31,41}$. It remains open and relatively unobstructed until the second decade of life ${ }^{33}$. The majority of the central canal is elliptical ${ }^{42}$, although 
variations exist including dilations, outpouches and forkings ${ }^{43,44}$. Specific age-related morphological changes are summarized by Yasui et al. (1999) ${ }^{31}$.

Scattered amongst the ependymal cells are functionally and morphologically distinct tanycytes, which extend long basal processes to enwrap blood vessels or terminate on gray matter neurons and glia, aiding in CSF-capillary communication ${ }^{28,45,46}$. Tanycytes are likely a transitional cell between radial glia and ependymal cells and predominate during development ${ }^{28}$. In the mature central canal, tanycytes are the only cell expressing GFAP under non-injury conditions $^{47}$. There are also CSF-contacting neurons, observed more frequently in amphibians and lower vertebrates and occasionally in mammals, with well conserved properties across species. They likely regulate CSF pH and synapse with both local neurons and axons from higher segments of the spinal cord ${ }^{48-50}$. Further, a limited, immature subependymal population exists ${ }^{20}$ displaying heterogeneity in size, clustering, arrangement, and proximity to the ependyma ${ }^{34}$. Two general cell types have been described in this region that share features with type B (astrocytic stem cells) and C (TAPs) ${ }^{20,23} \mathrm{NSCs}^{51}$ from the mouse $\mathrm{SVZ}^{34}$, one of which includes GFAPreactive astrocytes ${ }^{20}$. The subependymal microenvironment consists of astrocytes expressing GFAP and Sox2, oligodendrocyte progenitors (OPCs) expressing Olig2, and NeuN mature neurons, all to a lesser extent relative to the SVZ subependyma ${ }^{20}$.

During fetal development, the ependyma has roles in axon guidance, motor neuron differentiation, nutrient transport and germinal blood vessel support, radial glia transformation, and arrest of neurogenesis. In the ventricles and central canal, they have roles in filtration of water, ions and small molecules from the CSF to the brain and spinal cord, protecting against potentially harmful substances ${ }^{28}$. Their cilia propel CSF, and their cell bodies act as a barrier between the fluid and parenchyma ${ }^{36}$. Ependymal cell actions during development are strongly 
affected by growth factor signaling. Indeed, they express brain-derived neurotrophic factor (BDNF) and its associated receptor tropomyosin receptor kinase $\mathrm{B}(\mathrm{TrkB})^{52,53}$, as well as glialderived neurotrophic factor (GDNF) and its associated receptors RET and GDNF receptor $\alpha^{54}$ (section 2.3).

\subsection{Stem Cell Properties}

To be considered NSCs, proliferating cells must form primary and secondary neurospheres during culturing and give rise to the three main CNS cells types ${ }^{11}$. The neurosphere assay is a widely used technique for stem cell isolation. Stem cells and their progeny proliferate in culture conditions when exposed to growth factors. At certain plating densities, their continued proliferation generates non-adherent, spherical cell clusters termed neurospheres. These can be dissociated, expanded and pooled (termed passaging) for further culturing and experimentation ${ }^{55}$. To be considered stem cells, new clones must be generated during repeated passages. This distinguishes them from progenitors, whose clones have limited capacity for self renewal ${ }^{56}$ and are incapable of generating new neurospheres beyond two passages ${ }^{35}$. Progenitors exist throughout the CNS, including the spinal cord, and are not considered stem cells given their ability to produce only a single cell type. OPCs, for example, give rise only to new, mature oligodendrocytes ${ }^{25}$.

Ependymal cells are the source of all stem cell potential in the spinal $\operatorname{cord}^{23,35,57}$. They are thus considered ependymal stem-progenitor cells (epSPCs). Heterogeneity in expression of stem cell and mature cell markers throughout the ependyma indicate that cells in different regions of the ependymal zone likely serve different functions ${ }^{20,58}$. epSPCs can self-renew via self-duplication ${ }^{35}$, producing multipotent daughter cells ${ }^{59}$ that do not leave the ependyma under 
normal conditions ${ }^{35}$. They produce neurons, astrocytes and oligodendrocytes in vitro, with exponential increases in cell numbers during neurosphere passaging ${ }^{35}$. Spinal cord astrocytes and OPCs, the latter of which is the major source of proliferation in the adult spinal cord, produce small numbers of clones unable to be passaged, do not differentiate into multiple cell types, and are thus not considered stem cells ${ }^{36,57}$.

epSPC self-renewal potential in mice decreases 14 -fold between postnatal day $10(\mathrm{p} 10)$ and $\mathrm{p} 21$, and a further 4 -fold from $\mathrm{p} 21$ to adulthood ${ }^{60}$. Astrocyte sensitivity towards oxidative stress, as well as overall physiology, changes with age, and consequent reductions in vascular endothelial growth factor (VEGF) and fibroblast growth factor-2 (FGF-2) signaling reduce the stem cell potential of neural stem and progenitor cells ${ }^{61,62}$, including epSPCs. Sex-determining region Y-box 2 (sox2), a transcription factor which functions in regulating pluripotent stem cells and maintaining $\mathrm{NSCs}^{63}$, is expressed throughout the ependymal region ${ }^{20}$. Those at the dorsal pole of the canal express markers of both neural and ependymal cells, and are likely the source of central canal stem cell potential in vitro or after injury ${ }^{25}$. Cells at the dorsal and ventral poles of the central canal are morphologically akin to radial glia, with similar apical-basal polarities as embryonic and adult $\mathrm{NSCs}^{58}$. The dorsal pole is also the site of greatest proliferation ${ }^{36}$. Indeed, expression of proliferation markers (Ki67) is over three times greater at the dorsal relative to ventral ependymal zones. They are also highly expressive of the neural stem cell markers nestin $^{20,35}$, Sox2, Musashi, Sox3, Sox9, FoxJ1, Notch1, brain lipid binding protein, Vimentin, CD133/prominin-1 and alpha-type platelet derived growth factor ${ }^{11,35}$. Expression patterns of these markers are heterogeneous, but the general profile appears to be conserved between nonmammalian vertebrates and mammals ${ }^{11}$. In the SVZ, neural progenitors are closely associated with blood vessels, as are proliferating epSPCs in the central canal, raising the possibility of 
hormonal and pharmacological influence. This vasculature association is necessary but not sufficient for stimulation of proliferation in vivo ${ }^{20}$.

There is scarce information on the signaling involved in the spinal cord stem cell niche compared to the other two aforementioned pools. Factors released from cells surrounding the niche direct stem cell proliferation and differentiation, and astrocytes affect epSPC fate ${ }^{25}$. Indeed, as in the SVZ, epSPC proliferation in vitro requires FGF-2, released by astrocytes ${ }^{25}$. Therefore, determining the molecules and pathways involved during both normal and injury conditions will be important to any future therapy requiring manipulation of epSPCs.

\subsection{A - Rodents and Mammals}

Mammals do not have complete functional regeneration after CNS injury, mainly as a result of an inhibitory glial environment ${ }^{60}$. In the SVZ, subependymal region TAPs mediate stem cell proliferation. Central canal epSPCs do not produce TAPs, and under normal conditions all epSPCs divide symmetrically, with daughter cells staying in the ependyma. Mitotic activity exists at low levels around the central canal, but PCNA (expressed during all stages of the cell cycle except G0) is more abundant in the lateral aspects and in cells in close contact with the $\mathrm{CSF}^{58}$. The neural stem cell properties of epSPCs likely differ based on their position in the spinal cord and at different stages of life (i.e newborns vs adults) ${ }^{22}$, but this has not been extensively characterized. Li et al (2016) found that epSPC stem cell potential is seen from postnatal day $10(\mathrm{p} 10)$ onwards, decreasing over time. Juvenile p21 mouse epSPCs respond only to severe SCI, as activities of other reactive glia are sufficient to seal all but severe injuries. Their greater capacity for recovery relative to adults is due to the differing reactivity levels of surrounding glia: resident astrocytes, microglia and pericytes display higher recovery-related 
reactivity than in adults and assume a more neurogenic, recovery-oriented role. Further, though SCI results in higher epSPC self-renewal capacity regardless of age, juvenile rodents show greater epSPC recruitment. epSPCs are therefore a backup mechanism in juvenile mice, recruited only when other reactive glia are incapable. They become the largest source of endogenous repair potential only during adulthood ${ }^{60}$.

During maturation, spinal epSPCs are the only ependymal cells or CNS progenitors in the body to express GATA3, a gene whose expression is typically restricted to differentiated neurons $^{22}$. In the spinal cord, its expression is restricted to V2b interneurons ${ }^{64}$. Almost all epSPCs are also positive for the transcription factor GAP-43, which functions in axon regeneration, synaptic regulation and neural development ${ }^{65}$. The central canal ependymal region shows similar immunoreactivity as forebrain ependymal progenitor cells, but with increased NG2 (neural/glial antigen-2, a CNS progenitor cell marker with roles in migration, proliferation and axon growth and guidance), Olig2 (oligodendrocyte transcription factor with roles in directing motor neuron fate, and promoting oligodendrocyte and neuron differentiation) and Mash1 (Mammalian achaete schut homolog-1, with roles in neuron commitment and differentiation $)^{25}$. Central canal epSPCs have greater basal proliferation levels than SVZ ependymal cells ${ }^{28}$. Indeed, ependymomas occur more frequently after trauma to the spinal cord than brain ${ }^{66}$. Further, neurospheres of epSPCs from injured spinal cords are up to 4 times larger than those formed from non-injured ${ }^{57}$.

Following SCI, the inflammatory environment surrounding the injury site induces both genotypic and phenotypic changes in the ependyma. epSPCs substantially increase their proliferation $^{35}$ during the first 2 weeks after injury ${ }^{11} .4$ months post-injury, epSPCs become the major source of new cells ${ }^{57}$ and are estimated to have been the source of over half of all new 
astrocytes. These are typically situated in the center of the glial scar, while those derived from astrocyte duplication are less concentrated and more spread in and around the injury area ${ }^{11,57}$. Indeed, the glial scar consists of a border region of reactive astrocytes, and a lesion core of migrating epSPCs and invading connective tissue ${ }^{60}$. They secrete extracellular matrix proteins that aid in lesion sealing but contribute to glial scarring ${ }^{36}$.

Rodent models of SCI show significant increases in epSPC neurosphere forming potential, capacity for self-renewal, and in vitro proliferation relative to those obtained from noninjured animals $^{57,67}$. In non-injured mice, average epSPC proliferation is $1-3$ cells/30 $\mu \mathrm{m}$ in coronal sections of cervical, thoracic and lumbar regions, increasing up to 10-15 fold in response to injury, with exact increases varying based on time post-injury and distance from injury site ${ }^{23}$. Increased neurosphere forming potential is accompanied by increased survival during serial passages. Further, injured epSPCs show significantly higher mRNA expression of Sox2 and Oct4, which play roles in stem cell self-renewal, potency, and differentiation, with inflammatory factors from injured tissue increasing VEGF/MAPK and Jak/Stat signalling ${ }^{67}$. Total ependymal cell number increases in a time and injury severity dependent manner. The more severe the injury, the greater the proliferative activity and the longer proliferation persists for ${ }^{65}$.

epSPCs show a characteristic spatiotemporal response to injury. Proliferation occurs rapidly near the region of injury, with magnitude decreasing at greater distances from the lesion and peaking at 3 days post-injury at the lesion site ${ }^{23}$. Early after injury, the central canal expands and epSPC proliferation increases only caudal and rostral to the lesion ${ }^{11}$. This increased proliferation comes after an initial decrease in mitotic cells, the extent and duration of which correlates with injury severity. Nestin and GFAP expression are also significantly increased following injury in both mice and rats ${ }^{65,68,69}$. epSPC reaction has been found to be restricted to 
the injury segment, even in adjacent regions damaged indirectly via Wallerian degeneration and axon damage ${ }^{35}$. Timelines may differ based on age, as young rats show maximum mitotic activity 2 days post-SCI, returning to near normal by 4 days $^{70}$, but slightly increased proliferation continues at lower levels beyond 4 days ${ }^{65}$. Macaque monkeys show increased proliferation in more distal regions of the spinal cord in response to injury relative to rodents ${ }^{71}$, suggesting species-related differences in epSPC properties.

Inhibition of epSPC proliferation significantly compromises the formation of the glial scar and reduces the survival of remaining neurons ${ }^{72}$. epSPCs migrate towards the site of injury and accumulate around the ends of damaged axons in the lesion and forming glial scar ${ }^{22,67}$, with small numbers found in the surrounding white and gray matter ${ }^{57}$. They are likely not a contributing factor to the growth-impeding environment ${ }^{35}$. epSPCs migrating out of the ependymal layer express sox 9 and minimally GFAP, losing Foxj1, Sox 2 and Sox 3 immunoreactivity and consequently stem cell capacity, indicative of differentiation. epSPCs produce sox 9 astrocytes, while resident reactive astrocytes produce GFAP positive astrocytes ${ }^{35}$.

epSPCs from injured rodents show a greater proportion of oligodendrocyte differentiation than uninjured controls ${ }^{67}$. However, epSPCs produce relatively low proportions of new oligodendrocytes relative to $\mathrm{OPCs}^{36}$. The signaling environment in the injured spinal cord opposes neuronal differentiation and is significantly pro-gliogenic ${ }^{23,73}$. Fate of differentiating epSPCs favours an astrocyte lineage (and oligodendrocyte to a lesser extent) regardless of transection or contusion injury model ${ }^{11}$. Effective neuronal differentiation is opposed even following transplantation of stem cells cultured towards a neuronal fate, with reactive astrocytes at the injury site secreting factors opposing neuronal differentiation ${ }^{73}$. Lineage tracing of differentiated epSPCs post-SCI show significantly larger numbers of GFAP reactive astrocytes 
in the scar compared to $\beta I I I-t_{\text {tubulin }}{ }^{26}$ or NeuN positive neurons ${ }^{35}$. Lineage tracing of epSPCs after SCI in macaque monkeys showed no neuronal differentiation ${ }^{71}$.

While neurons appear before glia in CNS development, NSCs from bone marrow, SVZ and hippocampal dentate gyrus all show preferences toward glial differentiation (11-18\% vs. $30-$ $64 \%$, respectively) ${ }^{74-76}$, and rodent epSPCs follow suit. In vitro, they are capable of differentiation into neurons (including GABAergic), oligodendrocytes and astrocytes ${ }^{20}$, with a general preference towards glial differentiation ${ }^{59,60}$. Cultures of uninjured epSPCs exhibit greater expression of GFAP, preferring an astrocytic fate under normal conditions ${ }^{67}$. Injured and uninjured epSPCs can be guided toward a 90\% motorneuron differentiation via the addition of several exogenous factors, including retinoic acid (RA) and $\operatorname{shh}^{67}$. Addition of EGF and FGF2 growth factors to the central canal following injury significantly increases proliferation and functional recovery ${ }^{77}$.

\section{$2.2 B-$ Humans}

Information on human epSPCs is relatively limited. Tissue gathered at autopsy from SCI patients cannot be controlled for given large variations in severity and location of injury. Details of fatal accidents may also be unreliable with regards to time between injury and death and delays from first responders. However, as in rodents, the neurosphere-forming capacity of the adult human spinal cord is restricted to the central canal region ${ }^{34}$. Human epSPCs produce neurospheres capable of differentiation into neurons even after one year of freezing, confirming their multipotency ${ }^{34}$. epSPCs from thoracic spinal cord of human donors aged 2-60 years old have survived 10 passages, with no chromosomal abnormalities. Cells from younger donors have higher mitotic indices, as measured by Ki67 expression ${ }^{78}$. Under basal conditions, epSPCs from 
thoracic and lumbar spinal cord do not significantly differ in expression of neural stem cell and proliferation markers, with the vast majority expressing nestin and sox 2 , and extremely low levels of GFAP, Ki67, and $4^{78}$. Young donors, however, show significant increases in proliferation (Ki67) and GFAP expression ${ }^{78}$. No expression of any of these markers appears in the surrounding white and grey matter.

Nestin is expressed by epSPCs ventrally, as is PSA-NCAM, a marker of immature neurons and neurogenesis ${ }^{34}$. In a study of embryonic and adult human spinal cords, nestin was expressed in dorsal and ventral regions of the central canal of adults only, with no correlation between increasing age and nestin expression levels. A positive correlation exists between levels of nestin expression and survival time after trauma, however significant variation exists between individuals $^{29}$. Nestin positive epSPCs at the dorsal pole have long basal processes extending into the spinal cord gray matter, a similar morphology to tanycytes, and may have roles in molecular transport from CSF to tissues. Nestin expression changes in response to injury are relatively widespread throughout the cord ${ }^{29}$. Sox 2 is highly expressed by epSPCs regardless of region. Most ependymal and surrounding cells also express Nkx6.1, a marker of progenitors for motorneurons and oligodendrocytes in the spinal cord. None of these cells display markers for proliferation under non-injured conditions ${ }^{34}$, making it likely that stem-progenitor cell characteristics are adopted only after injury, as in rodents. Under non-injury conditions, their ability to form secondary neurospheres is low, which fits with their low proliferation and selfrenewal in situ ${ }^{34}$.

Nestin is expressed in the human spinal cord ependyma in multiple sclerosis, amyotrophic lateral sclerosis (ALS), spinal tumours, and infants with hydrocephalus ${ }^{79-81}$. Nestin expression by epSPCs is increased by 4 times normal in multiple sclerosis patients compared to 
healthy controls, with ALS and spinal tumour patients showing similar increases ${ }^{29}$. When transplanted rostral and caudal to the lesion site in rats 1 week after compression SCI, human epSPCs differentiate into neurons, astrocytes and oligodendrocytes. They lose Ki67 expression 1 week after transplantation, suggesting a shift to a post-mitotic state ${ }^{78}$.

Human epSPCs can be propagated via the neurosphere assay, wherein they display markers of proliferation ${ }^{34}$. When cultured with bFGF and EGF, cell migration and process formation has been found to occur within 10 days, along with differentiation into $70-80 \%$ astrocyte and $10-20 \%$ neuronal fates. Minimal to no oligodendrocytes are seen ${ }^{34}$. Differentiated neurons show morphology consistent with an immature phenotype, displaying a single process and growth cone ${ }^{34}$. As in rodents, their differentiation can be guided by addition of exogenous factors to culture media.

\subsection{Exogenous Factors}

Adult stem cell fate is not determined by an internal preference based on region of origin, but instead by in vivo external signals. Rodent epSPCs produce little to no neurons in vivo, but in vitro studies have shown them capable of producing both neurons and glia - there is simply a lack of appropriate local cues in the body ${ }^{59}$. For example, the transcription factors Mash1, Olig2 and Pax6 promote neuronal differentiation of epSPCs in vitro ${ }^{82,83}$. Further, epSPC proliferation is increased and overall functional recovery after SCI improved after infusions of several growth factors $^{77,84}$, which have roles in neuron survival, synaptic plasticity, synaptogenesis, neurite branching, and modulation of electrophysiological properties ${ }^{85}$. NSCs embedded in a fibrin matrix with different combinations of the growth factors BDNF, platelet-derived growth factor (PDGF-AA), insulin-like growth factor 1 (IGF-1), EGF, basic fibroblast growth factor (bFGF), 
acidic fibroblast growth factor (aFGF), GDNF, and hepatocyte growth factor overcome the gliogenic microenvironment of the injured spinal cord and differentiate into neurons, with longdistance axon growth and integration into neural networks ${ }^{86}$.

In contrast to this, Parr et al (2008) found that $23.4 \%$ of rat epSPC neurosphere cells are positive for oligodendrocyte markers (RIP), followed by $2.8 \%$ for GFAP and $0.85 \%$ for neuronal markers ( $\beta$ III-tubulin $)^{87}$, suggesting at least some intrinsic fate preference. Lineage plasticity is still evident in human epSPCs based on external cues ${ }^{34}$. Dibutyryl-cyclic AMP (dbcAMP) significantly induces neuronal differentiation to levels 19 times that of fetal bovine serum (FBS) control, with $54.4 \%$ of cells expressing the neuronal marker $\beta$ III-tubulin. PDGF-AA promotes significant oligodendrocyte differentiation ${ }^{78}$.

This study will be the first to look at the intrinsic differentiation profile of human epSPCs cultured in FBS. Further, we will examine the electrophysiological properties of cells displaying neuronal markers from FBS cultures, as well as those in guided neuron differentiation media with the growth factors BDNF and GDNF, as well as with RA.

\section{$2.3 A-F B S$}

FBS was first used in cultures of ESCs as a source of hormones and nutrients ${ }^{88}$. Without external factors in the medium, neurosphere behaviour and fate are mediated by the properties of the adherent substrate ${ }^{89}$. FBS is currently the most universal component in the culture of numerous primary and immortalized cell types ${ }^{90,91}$. In cultures of hESCs, it promotes apoptosis of undifferentiated cells and spontaneous differentiation into cardiomyocytes ${ }^{92}$. It is also essential for iPSC generation, promoting cell proliferation and survival during reprogramming. It increases proliferation in a concentration dependent manner, downregulating the pro-apoptic 
tumour suppressor gene $\mathrm{p} 53^{91}$. Its constituents are not fully defined, but it is known to contain growth factors, hormones, iron transporters, vitamins, amino acids, and carbohydrates ${ }^{93}$, as well as components inducing stem cell differentiation and replication, as well as those affecting plating efficiency ${ }^{88,90}$. EGF, PDGF, IGF and insulin are FBS components likely involved in functional proliferation, iPSC reprogramming, and promotion of differentiation ${ }^{91}$. Unfortunately the exact factors and pathways through which it acts on individual cell types has not been extensively characterized ${ }^{93}$.

FBS acts as a buffer, acting with culture media to protect cells in vitro from extreme changes in $\mathrm{pH}$. It binds antibiotics, necessitating higher concentrations to be added to the culture medium to protect cells from infection ${ }^{90}$. FBS is approved for in vitro expansion of hESCs and iPSCs in clinical trials ${ }^{91}$. Soluble FBS in culture medium induces cell migration out from neurospheres, process outgrowth, and differentiation into protoplasmic cells ${ }^{89}$. In rat epSPC cultures, FBS treatment leads to a glial fate during differentiation, with minimal neurons as determined by GFAP and $\beta$ III-tubulin expression ${ }^{59}$. Human epSPCs cultured in FBS show limited differentiation, with $1.5 \%$ of cells expressing the neuron marker $\beta$ III-tubulin, $1.1 \%$ NF200 (another neuron marker), 1.3\% O4 (oligodendrocyte marker), and 0.2\% GFAP. Oligodendrocyte differentiation and overall cell proliferation decrease over time ${ }^{78}$. Our experiments will use FBS to look at the intrinsic fate preference of human epSPCs.

\section{$2.3 B-B D N F$}

BDNF is a polypeptide growth factor expressed throughout the $\mathrm{CNS}^{94}$ with extraordinarily diverse roles in directing CNS growth and differentiation during development ${ }^{53,95}$. It acts mainly through binding to TrkB receptors, leading to receptor 
dimerization, kinase activation and autophosphorylation, adaptor protein recruitment, and ultimately the activation of PI3K/Akt, MAPK/ERK, Jak/Stat, PLC/PKC, NFKB and RAS/ERK pathways, amongst many others. The extensive BDNF signaling pathways are summarized by Sandhya and colleagues (2013), with crucial roles in all neuron developmental processes ${ }^{94-97}$. Its actions through the JAK/STAT pathway result in neurite outgrowth ${ }^{94}$, while neurogenesis requires its activation of MAPK/ERK signaling ${ }^{95}$, and its neuronal progeny are typically dopaminergic $^{98}$ or GABAergic ${ }^{99}$ neurons. Intraventricular injections of BDNF into rat brains induces neurogenesis and dendrite and axon branching ${ }^{100}$ in numerous brain regions, including from ependymal cells in the $\mathrm{SVZ}^{101}$ and granule cells of the dentate gyrus ${ }^{102,103}$.

In vitro, $\mathrm{BDNF}$ promotes the survival, neurite outgrowth and differentiation of many cell types from many organs, including rat NSCs. Through its MAPK, AKT and STAT3 signaling it promotes NSC proliferation ${ }^{104}$. Crosstalk of BDNF and Wnt/ $\beta$-catenin signaling pathways via the MAPK/ERK pathway was also found to increase NSC proliferation and differentiation ${ }^{96}$, which fits with the important role of $\mathrm{Wnt} / \beta$-catenin signaling in the expansion and differentiation of numerous stem cell types ${ }^{105}$. These same pathways also synergistically promote the proliferation and differentiation of hepatic progenitor cells ${ }^{106}$, and Wnt/ $\beta$-catenin crosstalk with PI3K/AKT results in similar effects in hematopoetic stem cells ${ }^{107}$. BDNF also regulates axon morphogenesis ${ }^{96}$. Compared to FBS alone, addition of BDNF to culture promotes a significant increase in neuronal differentiation (as measured by $\beta I I I-t u b u l i n$ expression) and neurite outgrowth, an effect which diminishes with time in culture as a result of a critical period in differentiation being reached, wherein BDNF is no longer required for further differentiation and survival ${ }^{108}$. Neural precursors derived from human embryonic tissue injected into the auditory nerve of mice show significantly more proliferation, substantially greater numbers of 
differentiated neurons, and significantly more fiber outgrowth when BDNF is included in the injection ${ }^{109}$. Cultured hESCs from umbilical cord blood show significantly more GABAergic neural differentiation ${ }^{99}$ through MAPK/ERK signaling an upregulation of p35 (a neuron-specific gene that activates cyclin-dependent kinase 5 , required for proper CNS development ${ }^{110}$ ) and greater survival of neuron-like cells when BDNF was present, with PI3K/Akt and MAPK/ERKdependent upregulation of the anti-apoptotic B cell lymphoma 2 gene $^{97}$.

In vitro, BDNF differentiation results in a more neuron-like morphology, with longer, thinner shapes and branching processes, as compared to cultures without BDNF that remain flat with short extensions ${ }^{99}$. Bacterial meningitis signals the proliferation of endogenous NSCs in the rat hippocampus, but inhibits their neurogenesis. Exogenous BDNF application significantly increases their neuronal differentiation ${ }^{111}$. Multipotent astrocytic stem cells grafted into rodent stroke models show significant increases in migration towards an injury site and neuronal differentiation (as measured by $\beta$ III-tubulin expression) when BDNF and GDNF are present, with higher survival and decreased apoptosis ${ }^{12}$. The differentiation of hippocampal neural precursor cells into functional neurons depends on the activity-dependent secretion of BDNF by pre-existing mature neurons, with BDNF mediating communication between active neurons and TrkB-expressing progenitors ${ }^{113}$. Similar effects are found in inducing neuronal differentiation and in vitro survival of rodent SVZ ependymal cells ${ }^{114}$.

Given all the evidence of increased stem cell survival and neuronal differentiation in the presence of BDNF, we will use this neurotrophic factor to promote in vitro epSPC neuronal differentiation and survival. 
GDNF is a growth factor that signals through the RET receptor tyrosine kinase and GDNF receptor $\alpha^{115,116}$ to promote neuronal maintenance and regeneration, with certain motor neurons requiring GDNF signaling to avoid apoptosis ${ }^{116}$. Its regulation of the bcl6b transcription factor makes GDNF the primary neurotrophic factor involved in spermatogonial stem cell selfrenewal ${ }^{117}$. In cultures of the developing neural crest, GDNF has been shown to promote the development of several neuronal phenotypes, most notably adrenergic ${ }^{115}$, both in vitro and in vivo, often working as a cofactor with $\mathrm{BDNF}^{118}$. In the midbrain, it has roles in dopaminergic neuron development ${ }^{115}$, and increases the survival of said neurons in a 6-hydroxydopamine model of Parkinson's disease ${ }^{119}$. Transplants of NSCs into the striatum of rodents in said Parkinson's disease models show increased survival and reduced apoptosis if treated with GDNF in vitro prior to transplantation ${ }^{120}$. Neuroblasts during development are guided towards a dopaminergic neuronal fate by GDNF, whose actions through the RET receptor increase the expression of tyrosine hydroxylase $(\mathrm{TH}) \mathrm{mRNA}$ and protein levels, promotes $\mathrm{TH}$ gene transcription, and increases TH mRNA stability ${ }^{121,122}$. Transfection of the GDNF gene into bone marrow mesenchymal stem cells results in increased neuronal differentiation in vitro, both by itself and when acted upon by further differentiation agents ${ }^{85}$. It increases the proliferation and differentiation of dentate gyrus neural progenitors in vivo ${ }^{123}$ and in vitro, with signaling through the STAT3 pathway leading to a majority astrocytic fate. In vivo, its effects on existing astrocytes occupying the neurogenic niche indirectly increase progenitor proliferation ${ }^{124}$. However, in serum free conditions, GDNF significantly increases both the overall and neuronal differentiation of mouse mesencephalic ESCs (as determined by $\beta$ III-tubulin expression), with no significant change in GFAP astrocyte differentiation. Differentiated neurons were dopaminergic, 
a phenotype achieved via GDNF signaling through the Lmx $1 / \operatorname{Ptx} 3$ pathway ${ }^{125}$. Given its promotion of neuronal differentiation and frequent BDNF co-factor action, GDNF will be used in combination with BDNF to promote epSPC neuron differentiation and survival.

\subsection{D - Retinoic Acid}

Retinoic acid (RA) is a derivative of vitamin A, with crucial roles in regulating cell morphogenesis, growth, proliferation and differentiation ${ }^{126}$. RA induces the neuronal differentiation, proliferation and maturation of numerous stem cell types in vitro and in vivo, even in stem cells of non-neuronal origin ${ }^{127-129}$. RA regulates proliferation-differentiation switches of numerous progenitor and stem cell populations, with roles in somitogenesis, axial elongation, neurogenesis in numerous developing nervous system regions, and cardiogenesis. It is extensively produced by retinaldehyde dehydrogenase 2 during embryonic development, and diffuses into the neural plate to act on neural progenitors, which express the RA receptor, in turn signaling its direct target HoxA1, a necessity for stem cell neuronal differentiation ${ }^{130}$. Given its robust and extensive neuronal differentiation capabilities, RA will be used to promote epSPC neuronal differentiation.

\subsection{Study Rationale}

Two strategies exist in using stem cells to treat CNS injuries: 1) transplantation of pluripotent or multipotent stem cells guided towards a specific fate in vitro into the in vivo injury region; and 2) modulation of the microenvironment of a resident stem cell population so as to produce the necessary tissue for functional regeneration. To that end, multipotent NSCs are an ideal cellular target given their ability to only produce neurons and glia ${ }^{78}$. Major cellular differences exist between rodents and humans, notably in the comparative stem cell properties of 
ependymal cells in both the $\mathrm{SVZ}^{131}$ and central canal. It is therefore vital to examine the human correlates of studied rodent models whenever possible.

In an epSPC guided differentiation study using recombinant human BDNF, GDNF and shh, $90 \%$ of differentiated epSPCs stained positive for the neuron marker $\beta$ III-tubulin within 25 days in culture. However, only $32 \%$ of these cells showed mature electrophysiological properties $^{67}$, indicating a majority immature phenotype. In human epSPCs, Dromard and colleagues (2008) observed $\beta$ III-tubulin expression within 10 days in differentiation media, each displaying $\mathrm{K}^{+}$currents and a smaller subset displaying $\mathrm{Na}^{+}$currents $^{34}$. Using NT3, BDNF and IGF, differentiated hESCs expressing $\beta$ III-tubulin all show action potential firing within 3 weeks in culture ${ }^{132}$. Neural progenitor cells from embryonic rat telencephalons and hippocampi expressing $\beta$ III-tubulin fire action potentials and are electrically excitable within 7-12 days in differentiation media ${ }^{133,134}$ These studies suggest that $\beta$ III-tubulin expression appears prior to, or at least in conjunction with, the development of functional electrophysiology in differentiating stem cells.

The passive electrophysiological properties of differentiating neurons also show characteristic changes. Membranes hyperpolarize to between -60 and -70 millivolts $(\mathrm{mV})^{135-137}$, capacitance increases to 20-50 picoFarards $(\mathrm{pF})^{134,138-140}$, and input resistance decreases from around 4 gigaOhms $(\mathrm{G} \Omega)$ to just over $1 \mathrm{G} \Omega^{134,138-140}$ in conjunction with development of active signaling and $\beta I I I-$ tubulin expression.

As such, determining the active and passive electrophysiological properties of neurons differentiated from human central canal epSPCs will inform future culture preparation, cell manipulation and treatment strategies for a plethora of neurodegenerative conditions. We will 
use FBS, BDNF, GDNF and RA in our culture preparation to assess the electrophysiological properties of non-injured human epSPCs in spontaneous differentiation conditions (FBS alone) and under guided neuronal differentiation (addition of BDNF, GDNF and/or RA to culture media). Passaging will be kept to under 3 passages, as Moreno-Manzano (2009) found that healthy rodent epSPCs did not survive beyond that threshold ${ }^{67}$. We will extend the differentiation media incubation period up to 10 weeks so as to determine the time point when action potentials first arise, and to elucidate the electrophysiological properties of differentiating human epSPCs over extended periods in culture.

We hypothesize that only a small subset of cells in FBS will express neuronal markers ( $\beta$ III-tubulin), and only a subset of these neurons will display characteristic mature neuron electrophysiological properties. A significantly greater proportion of neurons are expected in cultures with BDNF, GDNF and RA, and we hypothesize that these will display more fully mature electrophysiological neuronal properties compared to FBS alone.

\section{Methods}

Tissue Collection and Stem Cell Isolation

All experiments were performed in accordance with the Guide to the Care and Use of Experimental Animals (Canadian Council of Animal Care), with protocol approval by the Animal Care Committee of the Ottawa Hospital Research Institute. Rat thoracic spinal cord was harvested from adult female Sprague-Dawley rats. Human thoracic and lumbar spinal cord tissue was harvested from adult organ transplant donors. Patient next-of-kin consented to spinal tissue donation and procedures according to Ottawa Hospital Research Institute ethics protocols and policies. Dissection procedures were performed according to Mothe and Tator $(2015)^{141}$. 
Human spinal tissue was gathered from male $(n=8)$ and female $(n=3)$ organ donors aged 22-69. A 3-6 centimeter segment of thoracic and/or lumbar spinal cord was harvested into saline within 2 hours of aortic cross-clamping to maximize cell viability. Within 3 hours, the central canal region of the spinal cord segment was isolated by removing the meninges and overlying white and gray matter in Life Technologies dissection buffer consisting of PBS, HBSS, DGlucose, and penicillin-streptomycin. This segment was cut into 1 millimetre (mm) pieces. Minced central canal tissue was enzymatically dissociated in papain, consisting of Earle's balance salt solution, papain with L-cysteine and EDTA, deoxyribonuclease 1 (DNAse), and ovomucoid protease inhibitor with bovine serum albumin. The cell suspension was centrifuged at 300G for 5 minutes. The pellet was resuspended in a papain inhibitor (ovomucoid-containing medium), followed by a DNAse albumin-inhibitor. Another centrifugation was performed at 70G for 6 minutes, whereby the supernatant was discarded and the pellet suspended in EFH medium (20 ng/mL human recombinant EGF (Peprotech), 20 ng/mL bFGF2 (Peprotech) and $2 \mu \mathrm{g} / \mathrm{mL}$ heparin (Sigma)). The suspension was then filtered through a 40 micrometer $(\mu \mathrm{m})$ cell strainer for removal of myelin and free cell membrane fragments, before a final centrifugation at $300 \mathrm{G}$ for 5 minutes in EFH medium.

\section{Cell Culture}

Cell density was then counted using a haemacytometer and seeded into 6 well plates at a density of 20 cells $/ \mu \mathrm{L}$ on Matrigel (diluted 25x in serum free media (SFM), Corning) in SFM (Neurobasal-A medium, B27 supplement, 2 mM L-glutamine, $100 \mu \mathrm{g} / \mathrm{mL}$ penicillinstreptomycin) and hormone mix (1:1 DMEM/F-12, 0.6\% glucose, $25 \mu \mathrm{g} / \mathrm{mL}$ insulin, $100 \mu \mathrm{g} / \mathrm{mL}$ transferrin, $5 \mathrm{mM}$ HEPES, $3 \mathrm{mM}$ sodium bicarbonate, $30 \mathrm{nM}$ sodium selenite, $10 \mu \mathrm{M}$ putrescine, 20nM progesterone) supplemented with EFH. Primary cell cultures were incubated and left 
undisturbed at $37^{\circ} \mathrm{C}$ with $5 \% \mathrm{CO}_{2}$ and $20 \% \mathrm{O}_{2}$ for one week. Primary NSCs were fed with $\mathrm{EFH}$ via replacement of $50 \%$ of the medium twice weekly over 3 weeks. Once adherence, proliferation and confluence were observed, $100 \%$ of the media was replaced with fresh $\mathrm{EFH}$, with subsequent feedings in 2-3 day intervals.

Once NSCs approached confluency, subculturing into secondary cell cultures was initiated. NSCs were detached/passaged using accutase, and the suspension was collected and centrifuged at $300 \mathrm{G}$ for 5 minutes. The resulting pellet was resuspended in fresh media, counted with a haemocytometer, and replated at 10 cells $/ \mu \mathrm{L}$, forming neurospheres. Neurospheres were fed every 2-3 days over the next 10 days, then similarly dissociated and processed for treatment.

To assess the intrinsic differentiation profile of epSPCs, human and rat primary or secondary-derived NSCs were seeded at 2 cells $/ \mu \mathrm{L}$ in 96 well plates as an adherent layer in EFH for one week. Media was removed, washed with PBS, and replaced with $1 \%$ by volume FBS in SFM to allow NSCs to differentiate for 7 or 14 days. Guided differentiation involved addition of $50 \mathrm{ng} / \mathrm{mL}, 100 \mathrm{ng} / \mathrm{mL}$ or $500 \mathrm{ng} / \mathrm{mL}$ of RA or $20 \mathrm{ng} / \mathrm{mL}$ BDNF $+20 \mathrm{ng} / \mathrm{mL}$ GDNF, both with and without $1 \%$ FBS by volume to SFM. For cultures used in electrophysiological recordings, $12 \mathrm{~mm}$ glass coverslips were etched with $12 \mathrm{M} \mathrm{HCl}$, coated with Matrigel, and placed in 6 well plates. Subcultures were plated on these coverslips at densities of 250, 500 or 1000 cells/coverslip in the same intrinsic differentiation and guided differentiation media as previously described. Culture medium was replaced once a week for up to 10 weeks.

\section{Immunocytochemistry}

Cells were permeabilized using $0.3 \%$ Triton- $\mathrm{X}$ and blocked with $10 \%$ normal goat serum (NGS; Genotech) in PBS for 30 minutes prior to antibody incubation. Fixed epSPC cultures were 
then characterized via immunostaining against cell-specific markers. These include: mouse anti$\beta$ III-tubulin (1:1000; Santa Cruz); rabbit anti-GFAP (1:300, Millipore); mouse anti-O4 IgG (1:300, R\&D Systems); rabbit anti-sox2 (1:200, Sigma); and mouse anti-Nestin (1:500 for humans, 1:200 for rat, Santa Cruz). Primary antibody incubation lasted overnight at $4^{\circ} \mathrm{C}$, followed by incubation in respective fluorescent AlexaFluor 594/488 nm secondary antibody at $25^{\circ} \mathrm{C}$ for 2 hours in dark conditions. Cells were further counterstained with Hoescht (1:2000, Invitrogen). Within 24 hours, the phenotype of proliferating and differentiated cells was visualized with a Nikon Ti Eclipse Epifluorescence microscope. Ten representative images were taken from each 96 well plate, at 20x magnification so as to cover a uniform and widespread distribution of cells in each well. Images were then merged using Image $\mathbf{J}$ software, and total number of immunopositive cells were counted as a percentage of overall Hoechst labeled nuclei.

\section{Electrophysiology}

Individual coverslips were removed from culture well plates and placed under a Zeiss examiner A1 microscope at room temperature. Bath solution was artificial cerebrospinal fluid (ACSF), consisting of: $125 \mathrm{mM} \mathrm{NaCl} ; 3 \mathrm{mM} \mathrm{KCl} ; 26 \mathrm{mM} \mathrm{NaHCO} 3 ; 11.25 \mathrm{mM} \mathrm{NaH}_{2} \mathrm{PO}_{4} ; 2$ $\mathrm{mM} \mathrm{CaCl}_{2} ; 1 \mathrm{mM} \mathrm{MgCl}$; and $20 \mathrm{mM}$ glucose. Cultures were examined for cells visually identified as neurons using a DAGE MTI camera. Criteria included:

- Distinct membranes

- Fusiform or non-circular cell bodies with a three-dimensional rather than flattened morphology

- Minimal contact of soma with other cells

- Little to no apparent membrane blebbing or vesicles/debris within 
- At least one visible process thinner than the cell body itself

Micropipettes were prepared from 4 inch long thinwall glass pipettes from World Precision Instruments using a Sutter Instruments flaming micropipette puller. Heat and velocity setting were set so as to achieve a pipette resistance of between 6-14 megaOhms (M $\Omega$ ). Following pulling, micropipette tips were fire polished using a Narishige Scientific Instrument fire polisher. Once an isolated cell with above criteria was identified, micropipettes were filled with internal recording solution consisting of: $140 \mathrm{mM} \mathrm{K}$-gluoconate; $10 \mathrm{mM} \mathrm{NaCl} ; 10 \mathrm{mM}$ HEPES; 1 mM EGTA; $4 \mathrm{mM} \mathrm{Mg-ATP;} \mathrm{and} 0.2 \mathrm{mM} \mathrm{Na}_{2}$-GTP at a $\mathrm{pH}$ of $\sim 7.3$ and an osmolarity between 290-295 mOSM. Using a Scientifica micromanipulator, the micropipette tip was brought into contact with the membrane of the identified cell, and a whole cell patch clamp recording was performed. Electrophysiological recordings were acquired using Axon Digidata 1550 and Multiclamp 700B from Molecular Devices Axon Instruments, controlled through associated Clampex (pClamp 10) software.

Once the whole cell configuration was achieved, current clamp protocols were run at specific current injection steps, depending on the resting membrane potential. Standard starting steps were -20 by 5 picoAmperes (pA), but altered up to -100 by $20 \mathrm{pA}$ for low input resistance cells. Level of current injection steps was adjusted so each step represented a membrane potential change of approximately $10 \mathrm{mV}$. Following this, the same protocols were run while holding the resting membrane potential at $-50 \mathrm{mV}$ or $-60 \mathrm{mV}$. Following current clamp recordings, voltage clamp recordings of spontaneous currents were performed at $-60 \mathrm{mV}$ for $1-5$ minutes, depending on the presence or absence of spontaneous events. Membrane potential was then incrementally increased to $+40 \mathrm{mV}$, where another recording was performed for 5-10 
minutes to test voltage-dependent rectification of synaptic events. The potential was further increased to $+60 \mathrm{mV}$ and a third voltage clamp recording was acquired for 10 minutes.

Analysis

Trace analyses were completed in Clampfit 10.7 software. Capacitance was read off initial whole cell statistics from Clampex software during $5 \mathrm{mV}$ voltage steps. Resting membrane potential, input resistance, and decay constant were calculated for current clamp recordings. Resting membrane potential was measured and averaged during the rest period before initial hyperpolarizing current injection steps and adjusted for a calculated liquid junction potential of $14.6 \mathrm{mV}$ for the internal solution used. Input resistance was calculated from the average difference between baseline and steady state potential for hyperpolarizing and depolarizing current steps in the linear range. This was then divided by the size of the corresponding current injection step to give input resistance. Average spontaneous excitatory postsynaptic current amplitude and decay constant were calculated for voltage clamp recordings. Selected events possessed a stable baseline with no other major event occurring within $200 \mathrm{~ms}$ of the acquisition period. Detected events were aligned in pClamp software and averaged. Average trace was fit with the exponential equation $f(t)=\sum_{i=1}^{n} A_{i} e^{-t / \tau_{i}}+C$ to determine decay constant.

Shapiro-Wilk statistical tests were performed on all data sets to determine normal distribution. ANOVA and student's t-test statistical analyses were performed on normally distributed datasets, with post-hoc Tukey HSD. Non-normally distributed data were analyzed using Kruskal-Wallis and subsequent Dunn's Multiple Comparison post-hoc tests with Benjamini-Hochberg False Discovery Rate corrections to reduce type 1 error. Data are presented as mean \pm standard error. 


\section{Results}

\section{Human epSPCs Differentiate Towards a Majority Neuronal Fate}

To determine the spontaneous differentiation profile of human epSPCs compared to rodent, cells isolated from rat and human thoracic and lumbar spinal cords were cultured in $1 \%$ FBS by volume. Rodent tissue was harvested from adult female Sprague-Dawley rats, while human tissue was harvested from adult human organ transplant donors. Human tissue was gathered from both males $(\mathrm{n}=8)$ and females $(\mathrm{n}=3)$ aged $22-69$ with negative serology and lacking infections, as per organ donation guidelines. Tissue was harvested into neuro-protective saline within 2 hours of aortic cross-clamping, thereby maximizing cell viability. Within 3 hours of harvesting, meninges and overlying white and gray matter were dissected, and the remaining ependyma and paraventricular tissue were minced and enzymatically dissociated. Cells were plated, and neurospheres formed by epSPCs were subcultured before reaching confluence. Intrinsic proliferation and differentiation were assessed by replacing media with serum-free media and $1 \%$ FBS, while effects of guided differentiation were assessed via treatment with RA (at 500,100 or $50 \mathrm{ng} / \mathrm{mL})$, BDNF $(20 \mathrm{ng} / \mathrm{mL})$ and GDNF $(20 \mathrm{ng} / \mathrm{mL})$, both with and without FBS.

Consistent with previous literature, rodent epSPC progeny preferentially express astrocyte markers (GFAP), with smaller proportions expressing $\beta$ III-tubulin (neuronal marker) and minimal $\mathrm{O} 4$ (oligodendrocyte marker, Figure 1, n=5). Surprisingly, over $60 \%$ of human epSPCs differentiate into cells expressing $\beta$ III-tubulin, with levels significantly greater than those seen in rats. Little to no GFAP or O4 expression was observed at for human epSPCs after 1-2 weeks in differentiation media (Figure $1, n=4$ ). 
A

$$
\text { A }
$$
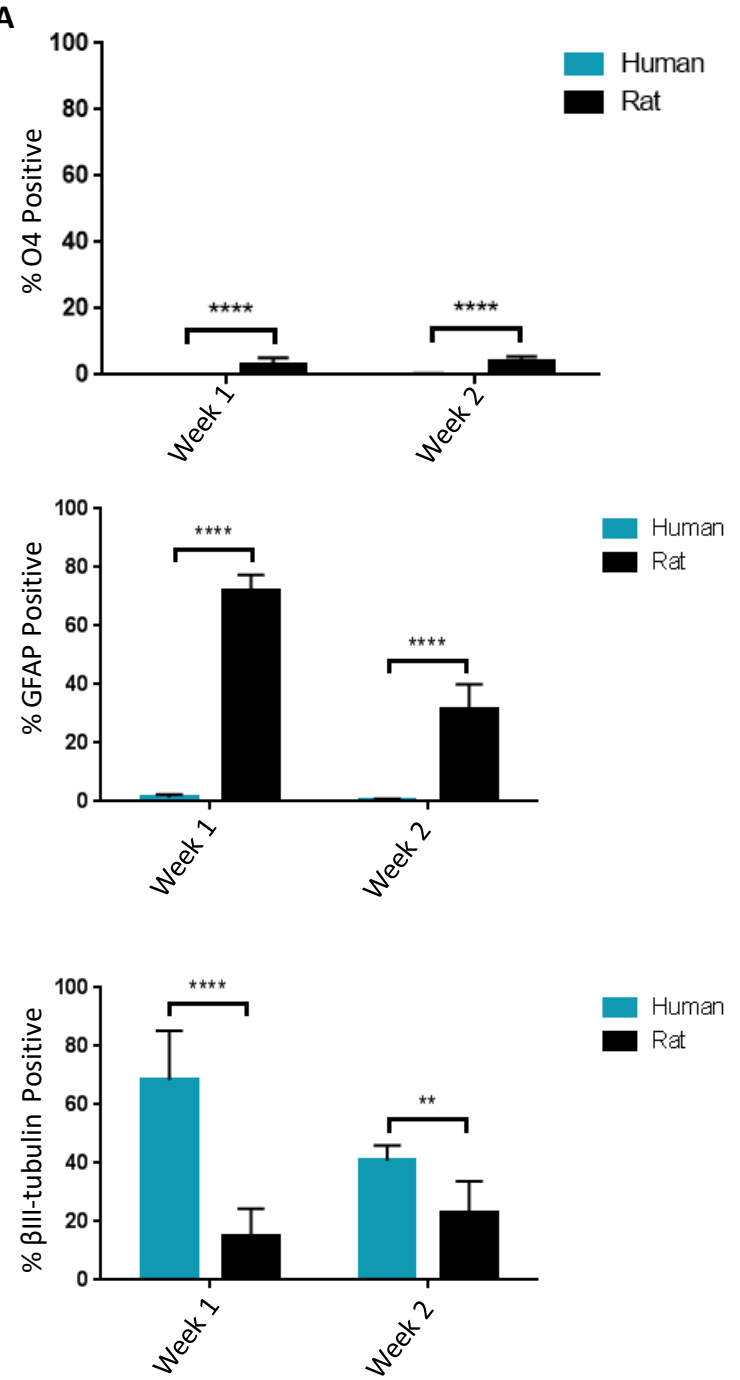

B
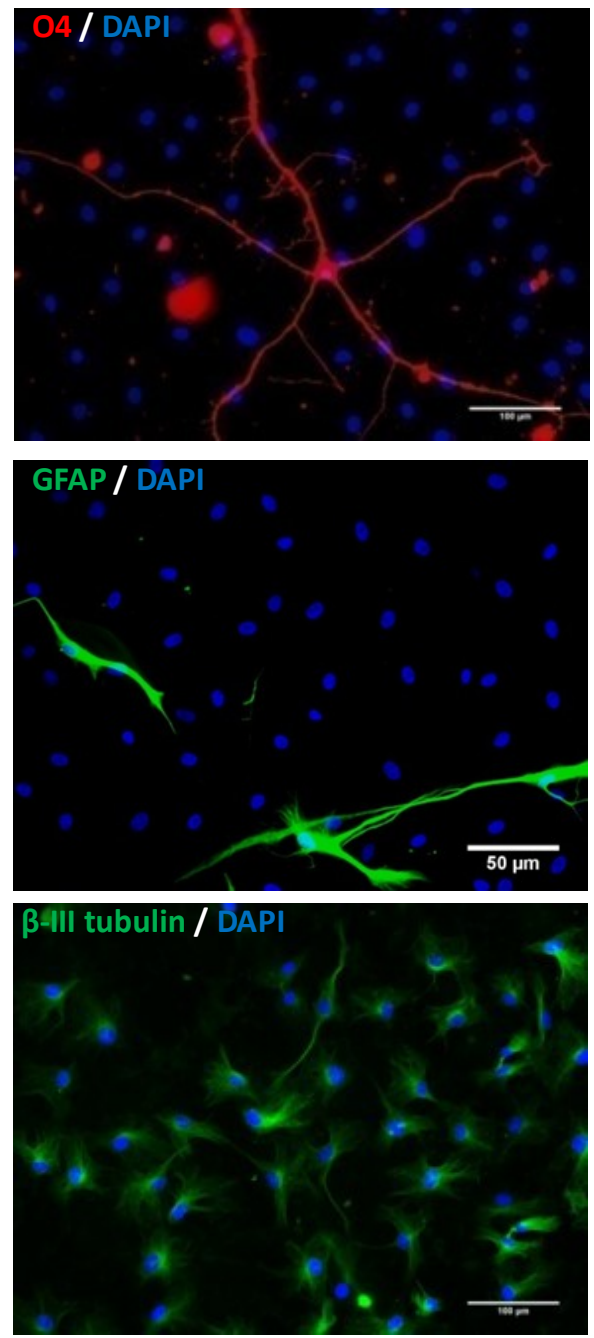

Figure 1: Differentiated human epSPCs preferentially express $\boldsymbol{\beta}$ III-tubulin. A) To assess intrinsic differentiation behaviour, collaborators cultured epSPCs in media containing 1\% FBS by volume and B) stained for oligodendrocyte (O4), astrocyte (GFAP) and neuronal ( $\beta$ III-tubulin) markers. Cell counts revealed rat epSPCs preferentially differentiate towards an astrocytic fate, whereas humans show significantly larger neuronal fate preference with almost no astrocyte differentiation. Further, rat epSPCs differentiate into significantly more oligodendrocytes than do humans $(\mathrm{p}<0.0001)$, who show little to no oligodendrocyte progeny. $* * p<0.001$, $* * * * \mathrm{p}<0.0001$

\section{Differentiating Human epSPCs Lack Action Potential Firing Up To 10 Weeks in vitro}

Given this difference in fate preference, we sought to determine the functional properties of human epSPC-derived neurons in vitro. EpSPCs were cultured in: FBS, to assess properties of neurons in intrinsic differentiation conditions; and RA, BDNF+GDNF and BDNF+GDNF+FBS conditions, to determine electrical properties of cells under conditions promoting neuronal 
differentiation. Seeded at 250,500 or 1000 cells per coverslip, cultures typically achieved confluence within 6-8 weeks. Cultures containing RA did not survive at $50 \mathrm{ng} / \mathrm{mL}, 100 \mathrm{ng} / \mathrm{mL}$ or $500 \mathrm{ng} / \mathrm{mL}$, with little to no observable viable cells from 2 weeks onwards in vitro (data not shown). As such, RA was abandoned as a differentiation agent. Cells in FBS, BDNF+GDNF and BDNF+GDNF+FBS conditions formed highly diffuse networks with few distinguishable cells matching typical neuron morphology (Figure 2A). Extensive expression of neuronal marker $\beta$ IIItubulin was observed, with a dense, diffuse staining pattern (Figure 2B). A smaller subset of differentiated epSPCs expresses the mature neuronal marker NeuN (Figure 2C).
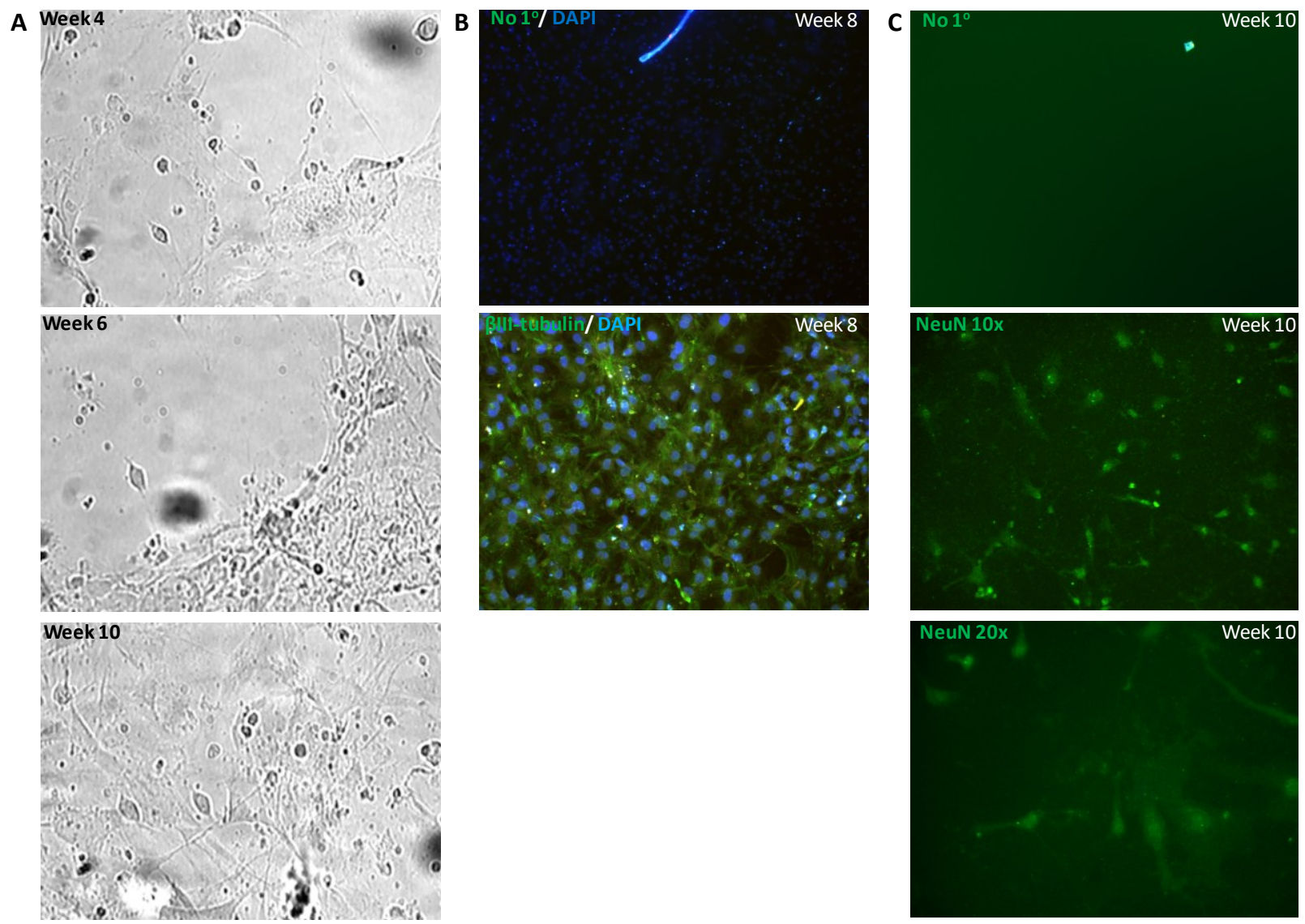

Figure 2: Differentiating epSPCs cultured on matrigel-coated coverslips express neuronal markers. A) Over ten weeks in culture, epSPCs seeded at 250, 500 or 1000 cells per coverslip achieve confluence, with higher cell numbers reaching confluence earlier. Cells were isolated from 11 human donors: 8 male, aged 22-64; and 3 female, aged 27, 36 and 69. Cells formed highly diffuse networks with few distinguishable cells matching typical neuron morphology. B) Extensive neuronal marker $\beta$ III-tubulin expression is seen, with staining patterns similar to the highly diffuse networks seen under light microscopy. C) A smaller subset of cells stain positive for the mature neuronal marker NeuN. 
To assess the electrical properties of putative neurons, current clamp recordings were performed. The criteria used for identifying putative neurons included: distinct membranes with three dimensional soma; fusiform or non-circular cell bodies; making minimal contact with other cells; displaying little to no apparent membrane blebbing or vesicles/debris within; and possessing at least one visible process thinner than the cell body itself (Figure 3A). Success in achieving whole cell patch clamping was low. Overall, $15.07 \%$ of cells were able to achieve a whole-cell patch clamp configuration after a gigaohm (G $\Omega$ ) seal ( $\mathrm{n}=77$ of 511 attempted): $22.31 \%$ in FBS $(\mathrm{n}=27 / 121) ; 14.69 \%$ in $\mathrm{BDNF}+\mathrm{GDNF}(26 / 177)$; and $11.27 \%$ in BDNF+GDNF+FBS (24/213). For all of these culture conditions, no cells recorded from weeks 2-10 in vitro displayed action potentials in response to depolarizing current steps (Figure 3B), even when the membrane potential was held at $-50 \mathrm{mV}$ or $-60 \mathrm{mV}$ (Figure $3 \mathrm{C}$ ).

We next sought to characterize the passive membrane properties of this cell population, reasoning that these would give clues as to the cells' relative developmental stage. Resting membrane potential (RMP) is the steady state condition of all cells at rest, arising from charge separation due to $\mathrm{K}^{+}, \mathrm{Na}^{+}$and $\mathrm{Cl}^{-}$gradients across the plasma membrane and its permeability to said ions ${ }^{136,142}$. Overall RMP was found to be significantly more hyperpolarized under FBS conditions $(-34.72 \pm 3.37 \mathrm{mV}, \mathrm{n}=27$ cells $)$ than BDNF+GDNF+FBS $(-20.91 \pm 2.81 \mathrm{mV}, \mathrm{n}=24$ cells, $\mathrm{p}=0.018) . \mathrm{BDNF}+\mathrm{GDNF}$ cultures were also more depolarized than FBS $(-27.03 \pm 2.40 \mathrm{mV}$, $\mathrm{n}=26$ cells $)$, but this failed to reach significance $(\mathrm{p}=0.178)$.

The input resistance $(\mathrm{Rn})$ of a cell is the relationship between the voltage change and current through the cells' membranes, reflecting the number of permeable "leak" ion channels along the membrane (cells with more leak channels have lower Rn) ${ }^{136}$. No significant differences 
exist in Rn between FBS $(1.04 \pm 0.17 \mathrm{G} \Omega, \mathrm{n}=22), \mathrm{BDNF}+\mathrm{GDNF}(1.23 \pm 0.18 \mathrm{G} \Omega, \mathrm{n}=25)$ and $\mathrm{BDNF}+\mathrm{GDNF}+\mathrm{FBS}$ culture conditions $(0.91 \pm 0.10 \mathrm{G} \Omega, \mathrm{n}=23 ; \mathrm{p}=0.956)$.

Capacitance $(\mathrm{Cm})$ is the measure of charge required to change cellular polarization, which determines how fast the membrane responds to changes in voltage and current. Indirectly, it is also a measure of membrane surface area, with a larger $\mathrm{Cm}$ correlating with larger cell size and/or more processes ${ }^{143,144}$. Both BDNF+GDNF $(28.42 \pm 3.70 \mathrm{pF}, \mathrm{n}=25, \mathrm{p}<0.001)$ and $\mathrm{BDNF}+\mathrm{GDNF}+\mathrm{FBS}(24.71 \pm 3.53 \mathrm{pF}, \mathrm{n}=24, \mathrm{p}<0.001)$ cultured cells had $\mathrm{Cm}$ values significantly higher than in FBS alone $(9.10 \pm 1.48 \mathrm{pF}, \mathrm{n}=15$; Figure 3E). To examine the distribution of $\mathrm{Cm}$ for cells across culture conditions, we grouped $\mathrm{Cm}$ based on $5 \mathrm{pF}$ increments (Figure 3F). The vast majority of FBS cells had capacitances between 5 and $10 \mathrm{pF}$, with no cells above $30 \mathrm{pF}$. Cultures containing BDNF and GDNF showed a more dispersed distribution, with the greatest single proportion of either in the $40+\mathrm{pF}$ group. Indeed, FBS cells show a normal distribution (Shapiro-Wilk, $\mathrm{p}=0.88$ ), while $\mathrm{BDNF}+\mathrm{GDNF}$ and $\mathrm{BDNF}+\mathrm{GDNF}+\mathrm{FBS}$ values are not normally distributed ( $\mathrm{p}=0.02$ and $\mathrm{p}=0.03$, respectively). 

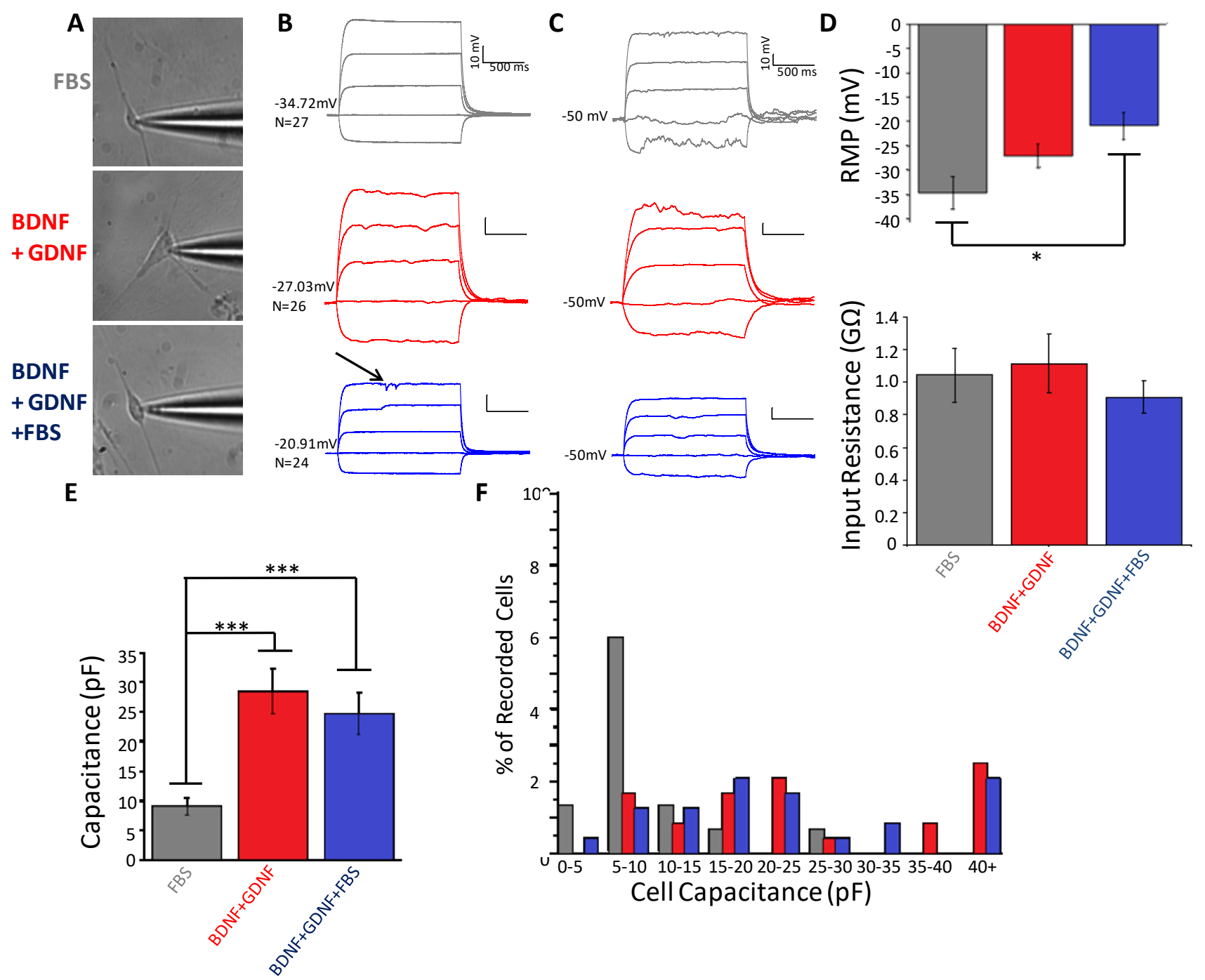

Figure 3: Differentiating epSPCs expressing neuronal markers do not fire action potentials. A) Cells with distinct membranes, fusiform or non-circular cell bodies making minimal to no contact with other cells, with little to no apparent membrane blebbing or condensed bodies within, and possessing at least one visible process thinner than the cell body itself were recorded from. Cell membrane health was poor regardless of culture condition, and patching success was low: overall $14.35 \% ; 22.47 \%$ for FBS; $14.70 \%$ for BDNF+GDNF; and $11.20 \%$ for BDNF+GDNF+FBS. Within this, only a small subset of cells survived through all current and voltage clamp protocols. Representative cells from FBS (top), BDNF+GDNF (middle) and BDNF+GDNF+FBS (bottom) are shown. B) Average resting membrane potential (RMP) for all cells recorded from each culture condition are shown for cells in culture from Week 2 to Week 10. Hyperpolarizing and depolarizing current steps at -20 by $5 \mathrm{pA}$ or -100 by $20 \mathrm{pA}$ failed to produce action potentials, even when C) membrane potential was held at $-50 \mathrm{mV}$ or $-60 \mathrm{mV}$. D) RMP is significantly higher under FBS culture conditions $(n=27)$ than BDNF+GDNF+FBS $(n=24)$. No difference in mean input resistance (Rn) exists between culture conditions. E) FBS cultures have significantly lower capacitances $(n=15)$ than cells cultured in BDNF+GDNF $(n=25)$ and BDNF+GDNF+FBS $(n=24)$, with F) $60 \%$ of all FBS cells having capacitances between 5-10pF. By contrast, cells cultured with BDNF and GDNF were more evenly distributed, with the greatest single proportions for each above $40 \mathrm{pF}$ ( $25 \%$ and $21 \%$ for BDNF+GDNF and $\mathrm{BDNF}+\mathrm{GDNF}+\mathrm{FBS}$, respectively). ${ }^{*} \mathrm{p}<0.05,{ }^{* * *} \mathrm{p}<0.001$. Arrow indicates one of several possible spontaneous postsynaptic potential-like events. 


\section{Time in Culture Has No Significant Effect on Passive Membrane Properties Up To 64 Days}

To test whether time in culture (TIC) reveals a trend towards the development of more stereotyped neuronal membrane properties (reduced input resistance, increased capacitance due to increased dendrite arborization and process development, and hyperpolarized RMPs between $40 \mathrm{mV}$ and $-90 \mathrm{mV}^{135,137}$, although mostly near $-65 \mathrm{mV}^{136}$ ), passive membrane properties were analyzed at three in vitro time points for each treatment group: weeks 2-4; weeks 5-6; and weeks 7-10 (7+). As neurons mature, RMP values are hypothesized to hyperpolarize as Rn values decrease, a result of changes in membrane expression of ion pumps and "leak" channels during development. Representative traces from BDNF+GDNF cultured cells at each time point are shown (Figure 4A), illustrating a lack of action potentials regardless of TIC. No significant differences exist for any measure within a culture condition between any analyzed time points ( $p>0.05$ for all comparisons). Cells were generally more hyperpolarized in FBS cultures at week 2-4 ( -39.82 $\pm 6.03 \mathrm{mV}, \mathrm{n}=7)$, weeks 5-6 $(-33.79 \pm 10.12 \mathrm{mV}, \mathrm{n}=6)$ and weeks $7+(-32.57 \pm 4.64$ $\mathrm{mV}, \mathrm{n}=14$ ) than in both cultures containing BDNF+GDNF, but this only reached significance in the latest time point compared to $\mathrm{BNDF}+\mathrm{GDNF}+\mathrm{FBS}$ cultures $(-13.13 \pm 1.24 \mathrm{mV}, \mathrm{p}=0.020$, $\mathrm{n}=8)$. BDNF+GDNF cultures were also more hyperpolarized than BDNF+GDNF+FBS at this time point $(-29.86 \pm 6.09 \mathrm{mV}, \mathrm{p}=0.03, \mathrm{n}=13)$. The $\mathrm{Rn}$ of BDNF+GDNF cells at weeks 5-6 (1.73 $\pm 0.29 \mathrm{G} \Omega, \mathrm{n}=6)$ was significantly higher than in FBS $(0.82 \pm 0.26 \mathrm{G} \Omega, \mathrm{n}=4, \mathrm{p}=0.042)$ and $\mathrm{BDNF}+\mathrm{GDNF}+\mathrm{FBS}(0.87 \pm 0.12 \mathrm{G} \Omega, \mathrm{n}=10, \mathrm{p}=0.030)$ cultures at the same time point, but this effect disappeared at the later time point. No other significant differences exist between culture conditions at any time. BDNF and GDNF containing cultures did not differ in $\mathrm{Cm}$ at any time point, but were consistently higher than cells in FBS alone. We therefore concluded that TIC did not significantly affect mean RMP (Figure 4B), mean Rn (Figure 4C) or mean Cm (Figure 4D). 
A

A Week 2

Week 6

Week 9
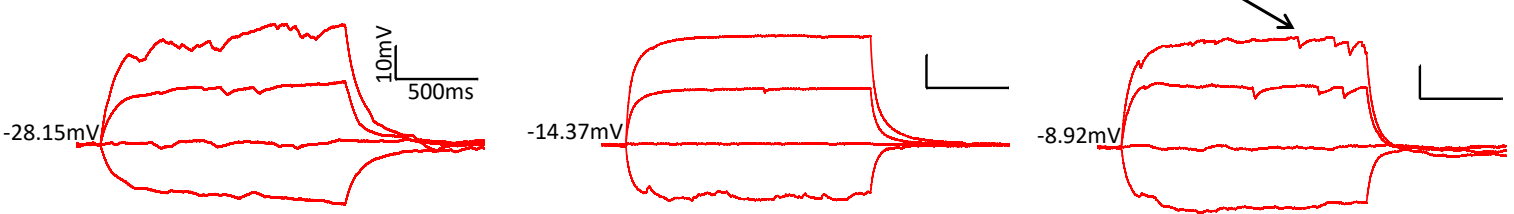

B

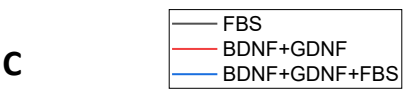

D
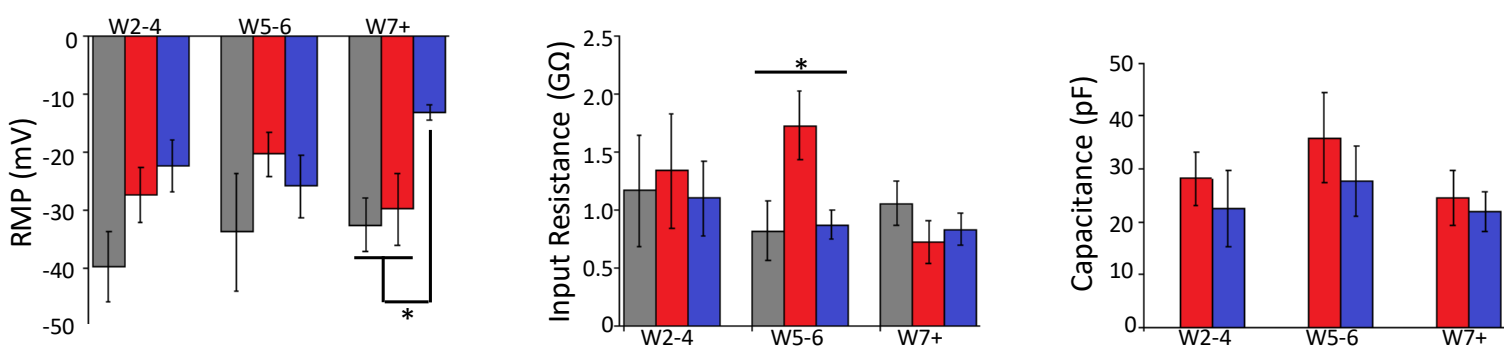

Figure 4: Time in culture has no significant effect on passive membrane properties. A) Representative current clamp recordings of cells from BDNF+GDNF cultures at different culture time points, illustrating lack of action potentials regardless of TIC. Time groups were: weeks 2-4 (W2-4); weeks 5-6 (W5-6); and weeks 7+ (w7+). RMPs of the representative cells are shown. TIC does not affect B) mean RMP, C) mean Rn, or D) mean Cm within any culture condition up to 10 weeks in vitro. Capacitance is consistently higher in cultures containing BDNF and GDNF from the earliest recording time points, while FBS alone cultures consistently have higher RMPs.

$\mathrm{BDNF}+\mathrm{GDNF}$ and FBS-alone cultures are significantly more hyperpolarized than BDNF+GDNF+FBS cultures only at Weeks $7+$ in culture $(* \mathrm{p}<0.05)$. Arrow indicates one of several possible spontaneous postsynaptic potentiallike events.

\section{FBS Produces Cells with More Hyperpolarized Membranes}

To determine whether specific passive membrane properties were correlated across cell subpopulations in a given treatment group, cells were grouped based on RMP into 0 to $-20 \mathrm{mV}$, 20 to $-40 \mathrm{mV}$, and $<-40 \mathrm{mV}$ categories (Figure 5A). The FBS cultures showed an even spread across the three groups, with the greatest concentration in the $<-40 \mathrm{mV}$ group. In contrast, cells cultured with BDNF and GDNF clustered in the relatively depolarized 0 to $-20 \mathrm{mV}$ range. None of the three treatment groups showed normal distributions (Shapiro Wilk $\mathrm{p}<0.05$ for each). FBS ( $\mathrm{n}=9,6$ and 7 for ' 0 to $-20 \mathrm{mV}$ ', ' -20 to $-40 \mathrm{mV}$ ' and ' $<-40 \mathrm{mV}$ ' groups respectively, $\mathrm{p}=0.55$ ), $\mathrm{BDNF}+\mathrm{GDNF}(\mathrm{n}=13,7,5, \mathrm{p}=0.10)$ and $\mathrm{BDNF}+\mathrm{GDNF}+\mathrm{FBS}(\mathrm{n}=15,7,1, \mathrm{p}=0.24)$ showed no 
significant differences in Rn between the RMP groups. When comparing RMP values between conditions at each group, no significant differences were present at 0 to $-20 \mathrm{mV}(\mathrm{p}=0.14),-20$ to $40 \mathrm{mV}(\mathrm{p}=0.93)$, and $<-40 \mathrm{mV}(\mathrm{p}=0.37) . \mathrm{Rn}$ for $\mathrm{BDNF}+\mathrm{GDNF}$ in the $<-40 \mathrm{mV}$ group $(\mathrm{n}=5,0.35 \pm$ $0.14 \mathrm{G} \Omega)$ appeared substantially lower than at either 0 to $-20 \mathrm{mV}(\mathrm{n}=13,1.32 \pm 0.28 \mathrm{G} \Omega)$ and -20 to $-40 \mathrm{mV}(\mathrm{n}=7,1.28 \pm 0.27 \mathrm{G} \Omega)$, but this failed to reach significance.

When performing the same analysis with cells grouped based on $\mathrm{Rn}$ (groups $<0.5 \mathrm{G} \Omega$, 0.5-1.0 G $\Omega$, and $>1.0 \mathrm{G} \Omega$ ), most FBS and BDNF+GDNF cells had Rn values above 1.0 G $\Omega$, while $\mathrm{BDNF}+\mathrm{GDNF}+\mathrm{FBS}$ cells clustered in the $0.5-1.0 \mathrm{G} \Omega$ range (Figure 5B). FBS (ShapiroWilk $\mathrm{p}=0.02)$ and $\mathrm{BDNF}+\mathrm{GDNF}(\mathrm{p}=0.02) \mathrm{Rn}$ values were not evenly distributed, while $\mathrm{BDNF}+\mathrm{GDNF}+\mathrm{FBS}$ values were $(\mathrm{p}=0.10)$. The RMP of cells in each $\mathrm{Rn}$ group were examined. In the lowest input resistance group, FBS $(\mathrm{n}=6,-47.55 \pm 4.80 \mathrm{mV})$ and $\mathrm{BDNF}+\mathrm{GDNF}(\mathrm{n}=8,-$ $39.39 \pm 8.07 \mathrm{mV}$ ) cultures were significantly more hyperpolarized than those with an $\mathrm{Rn}$ above $1.0 \mathrm{G} \Omega(\mathrm{n}=10,-25.67 \pm 4.38 \mathrm{mV}$ and $\mathrm{n}=11,-18.06 \pm 2.62 \mathrm{mV}$, respectively; $\mathrm{p}=0.042$ and $\mathrm{p}=0.020$, respectively). These results suggest that a subset of cells in FBS and BDNF+GDNF have a combination of more neuron-like passive membrane properties, with lower input resistances and more hyperpolarized membranes. 

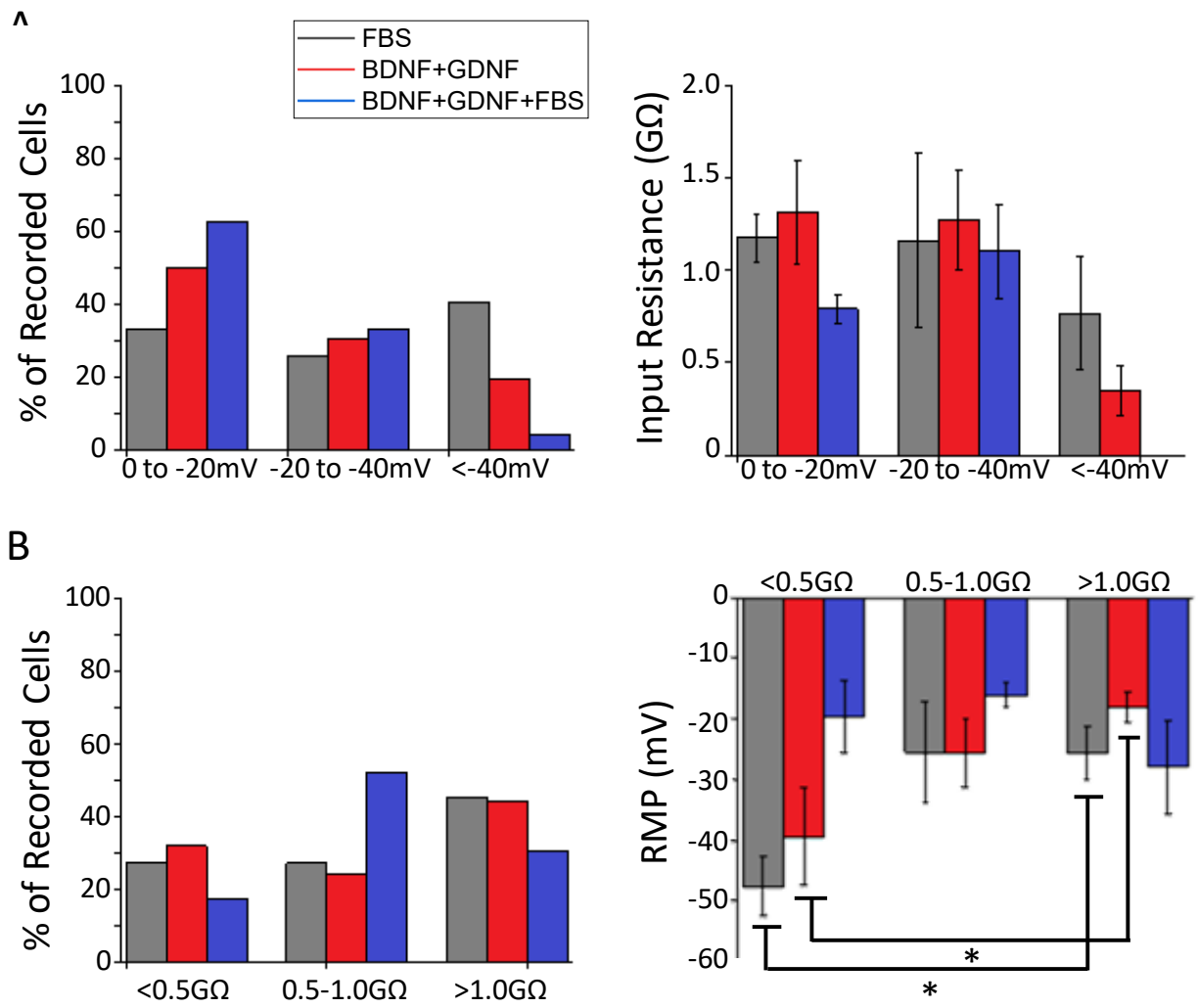

Figure 5: FBS produces cells with more hyperpolarized membranes. A) Left: When cells are grouped based on RMP into 0 to $-20 \mathrm{mV},-20$ to $-40 \mathrm{mV}$ and $<-40 \mathrm{mV}$ categories, FBS cultures show an even spread across the three groups, with the largest proportion more hyperpolarized than $-40 \mathrm{mV}$. This contrasts cultures containing BDNF and GDNF, which have minimal cells in the $<-40 \mathrm{mV}$ group, instead clustering in the relatively depolarized 0 to $-20 \mathrm{mV}$ range. Right: Input resistance does not differ between or within culture conditions at any of the RMP groups, nor does input resistance significantly change with RMP. B) Left: When a similar analysis was performed with Rn values, with groups of $<0.5 \mathrm{G} \Omega, 0.5-1.0 \mathrm{G} \Omega$ and $>1.0 \mathrm{G} \Omega$, most FBS and BDNF+GDNF cells had Rn values above $1.0 \mathrm{G} \Omega$, while BDNF+GDNF+FBS cells showed a majority 0.5-1.0 G $\Omega \mathrm{Rn}$. Right: As neurons become more mature, RMP values are expected to become more hyperpolarized and $\mathrm{Rn}$ is expected to decrease. Cells with lower input resistances in FBS $(n=6)$ and BDNF+GDNF $(n=8)$ cultures were significantly more hyperpolarized than cells with an Rn above $1.0 \mathrm{G} \Omega\left(\mathrm{n}=10\right.$ and $\mathrm{n}=11$, respectively; $\left.{ }^{*} \mathrm{p}<0.05\right)$. This effect was not seen in $\mathrm{BDNF}+\mathrm{GDNF}+\mathrm{FBS}$ cultures.

\section{Cells Lacking Action Potential Firing Show Synaptic Responses}

In current clamp recordings of membrane potential, a subset of cells appeared to show distinct spontaneous postsynaptic potential-like events at both hyperpolarizing and depolarizing steps (arrows in Figure 3B and Figure 4A). To better characterize these potential synaptic responses, voltage clamp protocols were performed on each cell at holding potentials of $-60 \mathrm{mV}$, $+40 \mathrm{mV}$ and $+60 \mathrm{mV}$. Of the cells healthy enough to survive current clamp procedures, the 
majority from FBS ( $\mathrm{n}=17,82.35 \%), \mathrm{BDNF}+\mathrm{GDNF}(\mathrm{n}=12,83.33 \%)$ and BDNF+GDNF+FBS $(\mathrm{n}=18,83.33 \%)$ cultures exhibited inward currents at negative holding potentials, and outward currents at positive potentials (Figure 6A). Frequency of events appears much higher at positive holding potentials than at negative (data not quantified). When averaged and analyzed, neither amplitude nor decay constant significantly differ between conditions at any holding potential (Figure 6B). When mean amplitude of synaptic currents of all cells at $-60 \mathrm{mV},+40 \mathrm{mV}$ and $+60 \mathrm{mV}$ are plotted, a relationship appears which may be linear with reversal potential above $0 \mathrm{mV}$. To better characterize this, the absolute values of event amplitudes at $-60 \mathrm{mV}$ and $+60 \mathrm{mV}$ for cells in each condition that displayed events at all three holding voltages were compared (Figure 6D). Amplitudes at $+60 \mathrm{mV}$ are larger than those at $-60 \mathrm{mV}$, but the low N's (FBS $\mathrm{n}=4$, $\mathrm{BDNF}+\mathrm{GDNF} \mathrm{n}=3, \mathrm{BDNF}+\mathrm{GDNF}+\mathrm{FBS} \mathrm{n}=3)$ fail to give this difference significance $(\mathrm{t}=0.053$ for $\mathrm{FBS}, \mathrm{t}=0.14$ for $\mathrm{BDNF}+\mathrm{GDNF}, \mathrm{t}=0.21$ for $\mathrm{BDNF}+\mathrm{GDNF}+\mathrm{FBS})$. This suggests that the observed spontaneous excitatory postsynaptic responses, present in the majority of cells for all culture conditions, are either outward rectifying or have a negative reversal potential (or both), with properties consistent with excitatory postsynaptic responses. 
A

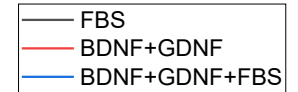

$-60 \mathrm{mV}$
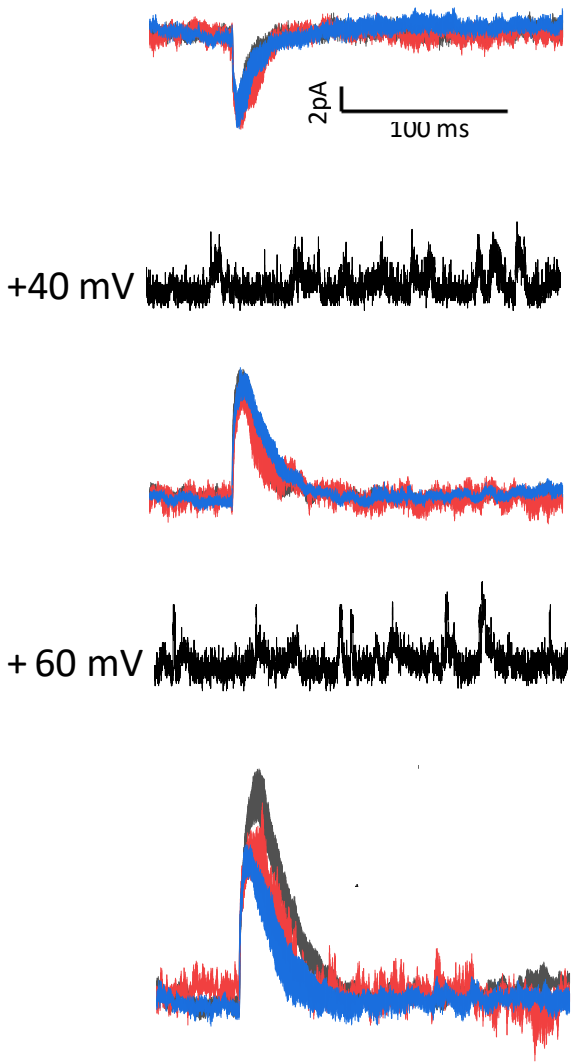
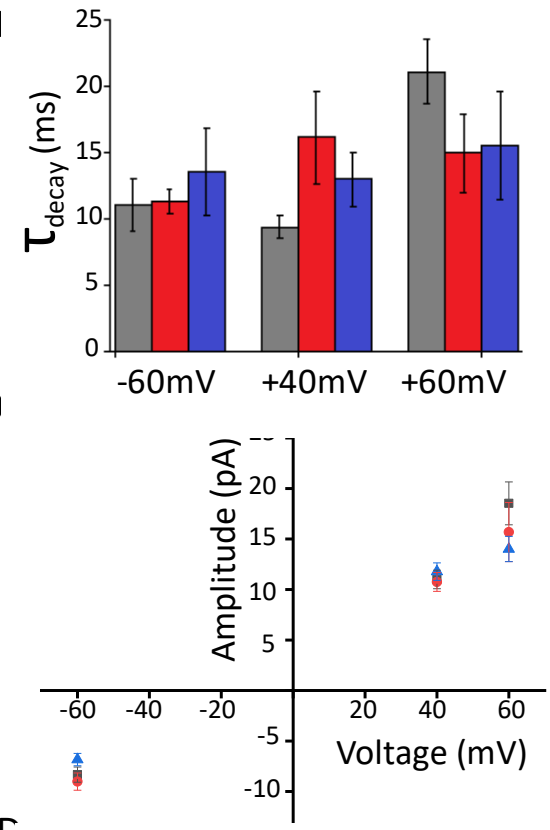

[

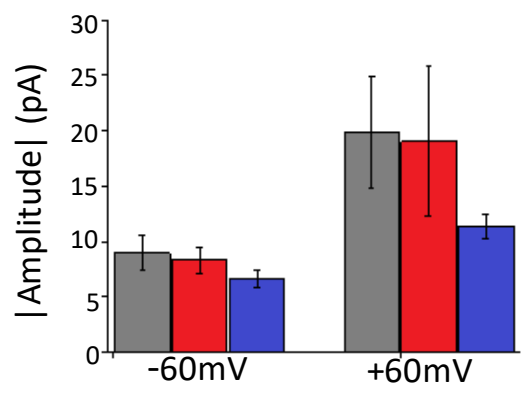

Figure 6: Cells lacking action potential firing display synaptic responses. A) Two second representative current clamp recordings at $-60 \mathrm{mV},+40 \mathrm{mV}$ and $+60 \mathrm{mV}$ holding potentials are shown in black. Frequency of events and event amplitude increases at positive holding potentials. Spontaneous synaptic currents were observed at all three observed holding potentials, with mean events at each holding potential for FBS (grey), BDNF+GDNF (red) and BDNF+GDNF+FBS (blue) cultures shown . Neither mean amplitude nor B) mean decay constant significantly differs between conditions at any holding potential. C) Plot of synaptic current amplitudes at $-60 \mathrm{mV}$ ( $\mathrm{n}=10$ for FBS, $\mathrm{n}=5$ for $\mathrm{B} / \mathrm{GDNF}, \mathrm{n}=6$ for $\mathrm{B} / \mathrm{GDNF}+\mathrm{FBS}$ ), $+40 \mathrm{mV}$ ( $\mathrm{n}=11$ for $\mathrm{FBS}, \mathrm{n}=8$ for $\mathrm{B} / \mathrm{GDNF}, \mathrm{n}=14$ for $\mathrm{B} / \mathrm{GDNF}+\mathrm{FBS}$ ) and $+60 \mathrm{mV}(\mathrm{n}=12$ for FBS, $\mathrm{n}=7$ for $\mathrm{B} / \mathrm{GDNF}, \mathrm{n}=8$ for $\mathrm{B} / \mathrm{GDNF}+\mathrm{FBS}$ ), and $\mathbf{D}$ ) comparison of absolute amplitude values at $-60 \mathrm{mV}$ and $+60 \mathrm{mV}$ for FBS $(\mathrm{n}=4), \mathrm{BDNF}+\mathrm{GDNF}(\mathrm{n}=3)$ and BDNF+GDNF+FBS $(\mathrm{n}=3)$ cells surviving all three voltage clamp protocols illustrates amplitudes are larger at $+60 \mathrm{mV}$, but low $\mathrm{N}$ 's fail to give this difference significance.

\section{Mean Spontaneous Current Amplitude Does Not Change With TIC}

To determine whether TIC had any effect on the properties of these synaptic currents, cells were divided into weeks 2-6 and weeks 7+ in culture. To increase n's and to retain statistical power, timelines were shortened from those used previously. No significant difference 
in peak current amplitude was observed within or between FBS and BDNF+GDNF conditions between the two time points at $-60 \mathrm{mV}$ or $+60 \mathrm{mV}$ holding voltages (Figure $7 \mathrm{~A}$ ). $\mathrm{BDNF}+\mathrm{GDNF}+\mathrm{FBS}$ had a significantly lower amplitude at $+60 \mathrm{mV}$ at weeks $7+(\mathrm{n}=4,11.56 \pm$ $0.81 \mathrm{pA})$ than at weeks $2-6(\mathrm{n}=4,16.46 \pm 1.63 \mathrm{pA}, \mathrm{p}=0.04)$.

In examining the effect of TIC on decay constant, no significant difference was observed in decay constants at $-60 \mathrm{mV}$ between the two analyzed time points (Figure $7 \mathrm{~B}$ ). At $+60 \mathrm{mV}$, the decay constant of cells cultured in BDNF+GDNF was significantly higher at weeks 2-6 ( $\mathrm{n}=3$, $21.69 \pm 4.00 \mathrm{~ms})$ than at weeks $7+(\mathrm{n}=4,9.86 \pm 1.92 \mathrm{~ms}, \mathrm{p}=0.03)$. BDNF+GDNF+FBS cells showed a trend towards decreasing decay constants over time for events at $+60 \mathrm{mV}$ as well, but this did not reach significance $(\mathrm{p}=0.15)$. No other significant differences were noted. Events at $+60 \mathrm{mV}$ appeared to get faster across TIC for cells containing BDNF and GDNF. 
$A$
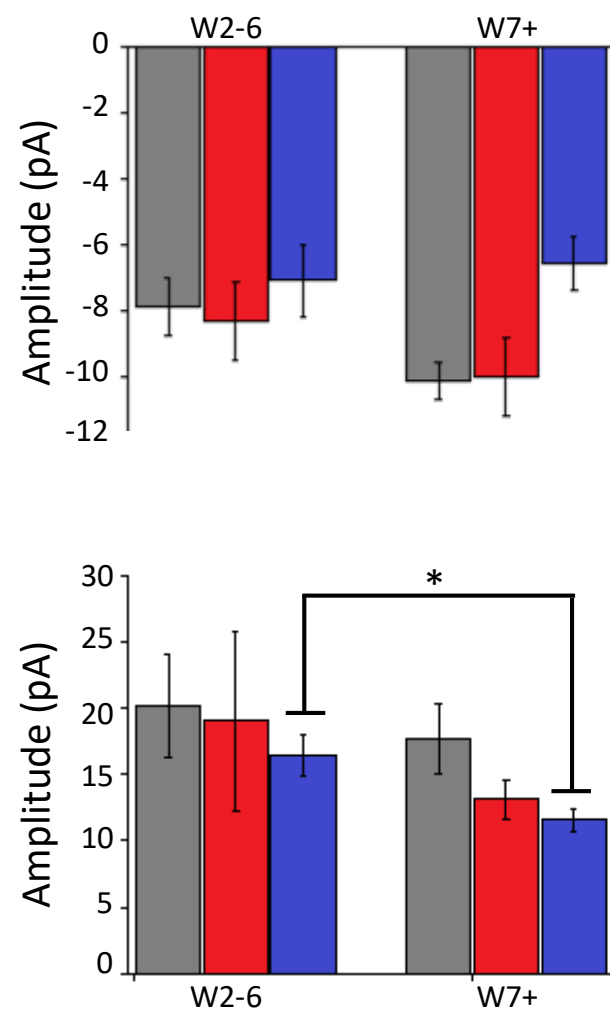
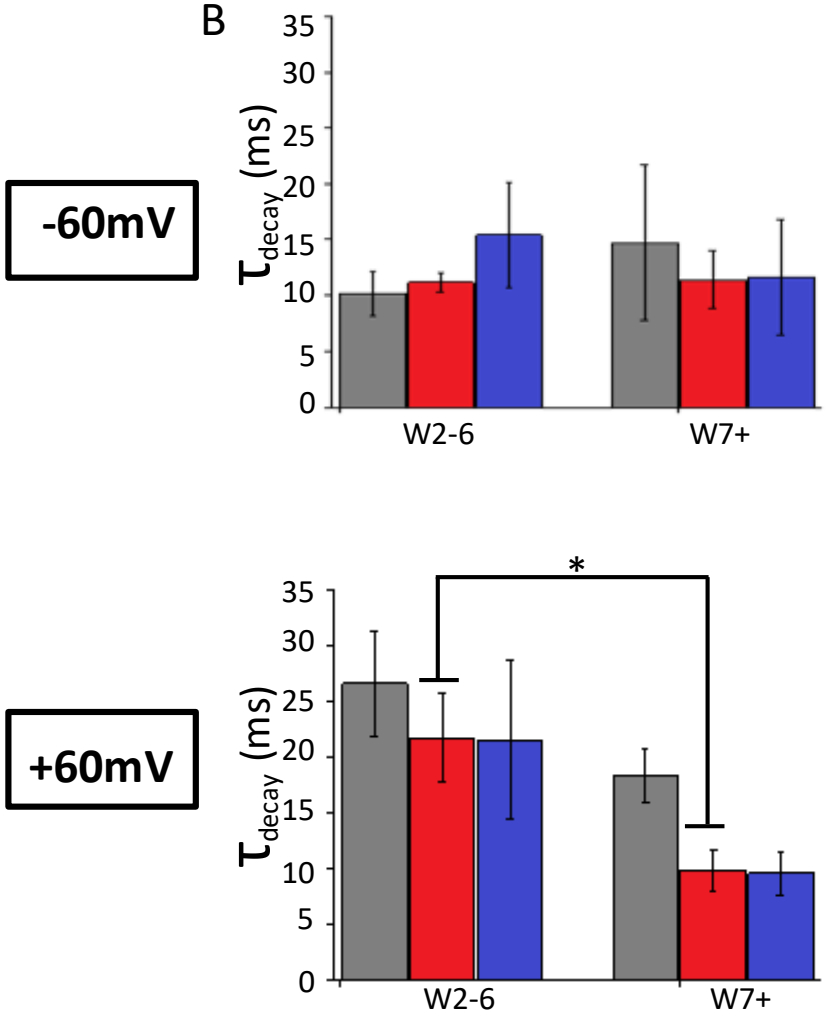

Figure 7: Time in culture decreases decay constant at positive holding potentials with no effect on amplitude. Mean amplitudes and decay constants were split into weeks 2-6 (W2-6) and weeks 7+ (W7+) in culture. No significant difference in mean amplitude was observed between the two time points at $-60 \mathrm{mV}$ or $+60 \mathrm{mV}$ holding voltages (A) in any culture condition except BDNF+GDNF+FBS, which had a significantly lower $+60 \mathrm{mV}$ amplitude at week $7+(n=4)$ than at week 2-6 $(n=4)$. B) No significant difference was observed between decay constants at $-60 \mathrm{mV}$ holding (top), while at the earlier time point, decay constant of $+60 \mathrm{mV}$ events in BDNF+GDNF after 2-6 weeks in culture $(n=3)$ was significantly higher than after 7 weeks in culture $(n=4)$.

\section{Discussion}

We observed that human epSPCs cultured in differentiation media show a preference towards a neuron fate, rapidly expressing $\beta$ III-tubulin with minimal astrocyte or oligodendrocyte marker expression. Electrophysiologically, however, these cells are not functional, lacking action potential firing up to the $10^{\text {th }}$ week in culture. Passive membrane properties (RMP, Cm, and Rn) do not reach mature neuron levels in this time period, and show no significant changes with TIC, suggesting a heterogeneous population of cells at multiple stages of differentiation. Surprisingly, these cells did exhibit fast spontaneous postsynaptic potentials with low amplitudes at $-60 \mathrm{mV}$, 
$+40 \mathrm{mV}$ and $+60 \mathrm{mV}$ holding potentials. The amplitudes were higher at $+60 \mathrm{mV}$ than at $-60 \mathrm{mV}$, suggesting either outward rectification or a reversal potential above zero.

\section{EpSPCs Exhibit a Neuronal Fate Preference}

Analysis of intrinsic differentiation preferences showed that rodent epSPC differentiation favours a majority astrocytic fate, with lesser neuron and oligodendrocyte progeny. This tendency for gliogenesis matches other differentiation studies on this cell population, both in vitro $^{59,60}$ and following SCI. Surprisingly, human epSPCs almost exclusively differentiated into cells expressing the neuronal marker $\beta$ III-tubulin, with almost no GFAP (astrocyte) or O4 (oligodendrocyte) expression. Little is known on this stem cell niche in humans, and reports are conflicting. In contrast to our findings, Dromard and colleagues (2008) looked at epSPCs from cervical, thoracic and lumbar spinal cords of donors 24-70 years old and, after 10-15 days in media containing $0.5 \% \mathrm{FBS}$, intrinsic differentiation analyses showed a $70-80 \%$ astrocyte (GFAP) fate and 10-20\% neuronal ( $\beta$ III-tubulin) fate, with rare oligodendrocyte marker (O4) expression $^{34}$. While coverslips were coated in laminin/poly-D-lysine (PDL) instead of matrigel, neither this nor the $0.5 \%$ FBS compared to $1 \%$ used in our study are likely to account for the drastic differences in fate preference. Matrigel is composed of collagen, heparin sulfate proteoglycans, TGF- $\beta$, EGF, IGF, FGF, tissue plasminogen activator, laminin, and entactin ${ }^{145,146}$. It has been used in expansion and differentiation studies of human and rodent ESCs, iPSCs, spermatogonial stem cells ${ }^{147,148}$ and NSCs, with little to no differences in differentiation compared to PDL ${ }^{148}$. The Dromard (2008) results were obtained only after a single passage, failing to successfully produce secondary neurospheres. As a result, these effects may have a glial progenitor contribution. However, this may also be the case in ours, as we only passaged once as well. Further, Dromard and colleagues (2008) gathered tissue from cervical, thoracic and 
lumbar spinal cord segments, and differences in epSPC differentiation between regions were not assessed. Future research examining whether epSPCs of different spinal cord segments exhibit different preferences in intrinsic differentiation will be useful to reduce any potential confounds. Despite this possibility, there is still no accounting for the complete inverse in differentiation preference. Future studies using more detailed fate mapping techniques into human epSPC differentiation are needed.

In another study looking at human epSPC isolation, culturing and in vitro differentiation, Mothe et al (2011) developed a method for serial passaging human epSPCs, successfully culturing them as monolayers over 9 months and through 10 passages. They found that thoracic epSPCs from donors aged 2-60, cultured on matrigel in media containing $1 \%$ FBS, exhibited low levels of overall differentiation. The major fate of the small proportion of cells that differentiated after 4 weeks was neurons expressing $\beta I I I-t u b u l i n ~(1.5 \%)$ and NF200 (1.1\%), followed by oligodendrocytes $(1.3 \% \mathrm{O} 4)$ and astrocytes $(0.2 \%)^{78}$. While this study used tissue from children, cells from the 2 year old showed a greater mitotic index (greater proliferation), with differentiation procedures producing far greater GFAP expression compared to adults ${ }^{78}$. The proportions observed in this study are more in line with our own with regards to a majority neuron fate, however the almost equal production of oligodendrocytes is novel - we observed almost no $\mathrm{O} 4$ production at both 1 and 2 weeks in culture. While this study used only thoracic spinal cord segments, none of our cultures showed significant levels of O4, thus in our study at least thoracic and lumbar spinal cords do not appear to differ in oligodendrocyte differentiation. Further, the use of child spinal cord tissue may account for differences in overall fate preferences of the culture, given the switch in regenerative responsibility from surrounding glia to epSPCs observed in juvenile vs. adult rodents ${ }^{22}$, as well as differences in epSPC properties between 
immature and mature animals ${ }^{60}$. Studies looking to characterize these differences are necessary for optimizing any epSPC-focused therapies.

Health of donor spinal cord may affect fate preference given the immense number of signaling molecules involved after CNS injury and their physically and temporally distant effects, but given the plethora of unique causes of fatality this cannot be controlled in human donor tissue beyond meeting organ donor criteria. The ability of these cells to undergo up to 10 passages may indicate some form of SCI, as Moreno-Manzano et al (2009) found that healthy rodent epSPCs did not survive beyond three passages, while those isolated from rats after SCI showed significantly greater proliferation and differentiation, undergoing many more passages ${ }^{67}$. This could also be an innate difference between healthy rodent and human epSPCs. Future work will need to be done to determine the genetic correlates of these intrinsic fate preferences, and whether epSPCs from injured and uninjured human spinal cord differ in preference.

\section{Cells Expressing BIII-Tubulin Are Not Functional, Fully Differentiated Neurons}

The vast majority of epSPC progeny in FBS, BDNF+GDNF and BDNF+GDNF+FBS differentiation media express $\beta$ III-tubulin (BDNF and GDNF counts currently ongoing). None of the cells showed fully differentiated neuronal morphology. Even after biasing for cells close to stereotyped neuronal morpohology (distinct membranes, at least one visible process thinner than the cell body itself, fusiform or non-circular cell bodies with a three-dimensional morphology), none displayed action potential firing in response to depolarizing current steps in any differentiation condition, even with membrane potentials held at $-50 \mathrm{mV}$ or $-60 \mathrm{mV}$. As such, these cells cannot be classified as functional neurons, even up to the $10^{\text {th }}$ week in culture. 
Electrophysiological recordings on neurons derived from epSPCs are rare in the literature

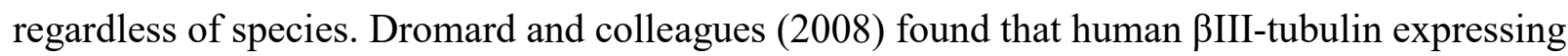
neurons showed voltage-gated $\mathrm{K}^{+}$currents in all cells, with a subset displaying voltage-gated $\mathrm{Na}^{+}$ currents. No recorded cells fired action potentials, indicating an immature neuronal phenotype ${ }^{34}$. None of the cells in our study displayed voltage-gated currents under current clamp protocols, nor in the preliminary voltage clamp experiments. By comparison, the Dromard et al (2008) differentiation procedure was 10-15 days (Week 2/3 under our timeline), and this lack of functionality may be due to insufficient time in differentiation media. When Moreno-Manzano and colleagues (2009) performed guided differentiation with BDNF, GDNF and shh on rodent epSPCs, $90 \%$ of progeny displayed markers for motorneurons (MAP2 and HB9). Voltage clamp recordings at $+60 \mathrm{mV}$ on the $25^{\text {th }}$ day (Week 4 under our timeline) showed that $22 \%$ and $32 \%$ of cells derived from uninjured and injured epSPC, respectively, had $\mathrm{K}^{+}$currents with single-spike action potentials ${ }^{67}$. As such, they concluded that only a small subset of the rodent epSPC-derived neurons displayed functional neuronal capacity, and that growth factor incubation should be extended for a more functional yield ${ }^{67}$. The discrepancy between levels of neural marker expression and functionality are in keeping with our findings in human epSPCs. However, despite more than doubling the incubation time in differentiation media relative to MorenoManzano and colleagues (2009), our findings in humans indicate that even up to Week 10 (day 64), no epSPC-derived cells are functional.

Neurons derived from other stem cell sources achieve functionality at substantially earlier time points than our latest epSPC recordings. A similar experiment looking at neurons differentiated from mouse embryonic fibroblast iPSCs found that by week 8 under our timeline, half of recorded cells displayed action potential firing. This represented a near 3-fold increase 
compared to cells cultured for 5-6 weeks in our timeline ${ }^{149}$. When hESCs are differentiated into spinal motor neurons via RA treatment, all cells fired action potentials between weeks 4-6, with a small subset displaying multiple spikes ${ }^{150}$. Differentiation of $\mathrm{hESCs}$ using $20 \mathrm{ng} / \mathrm{mL}$ of BNDF, GDNF and neurotrophin-3 (NT3) found that between weeks 4 and 5, single spike action potentials were observed, and by week 6 cells fired multiple spike action potentials ${ }^{151}$. Using NT3, BDNF and IGF, differentiated hESCs expressing $\beta$ III-tubulin all showed action potential firing within 3 weeks in culture ${ }^{132}$. BDNF, GDNF, Ascorbic Acid and cAMP differentiation protocols induced hESC neuron differentiation, with half of neurons firing action potentials by week 4 , and all firing by week $10^{140}$. Human neural progenitor cells from a developing cortex differentiated to glutamatergic neurons display polarized morphologies, with action potentials present from day week 8 in culture, although no repetitive firing was observed by the study endpoint of 61 days (Week 9) ${ }^{152}$. Given the substantial literature on other stem cell sources, it appears epSPCs from the human central canal require relatively lengthy incubations in differentiation media for the development of functional electrophysiological properties.

This timeline may be unique for human epSPCs even amongst CNS stem cells, as neural progenitors and NSCs from other CNS niches develop functionality at earlier time points than used in our study under similar differentiation conditions. Rat neural progenitors from the embryonic telencephalon, differentiated with NT3, cAMP and BDNF with or without FBS, fired action potentials within 1 week in differentiation media, with large voltage-gated $\mathrm{K}^{+}$and $\mathrm{Na}^{+}$ currents $^{133}$. Rodent hippocampal neuroprogenitors, differentiated using BDNF, NGF and NT3, showed both undifferentiated and differentiated phenotypes after 1-2 weeks in differentiation conditions. All differentiated cells were electrically excitable and fired action potentials ${ }^{134}$. Cultures of SVZ NSCs differentiated towards a neuronal fate, co-cultured alongside mature 
spiral ganglion neurons, show robust action potential firing after hyperpolarizing current injection within 2 weeks ${ }^{153}$. Embryonic mouse NSCs from the SVZ only fire action potentials after differentiation, and within 2 weeks neurons derived from embryonic, adult or aged mice fired action potentials, with no significant differences in threshold, amplitude or duration ${ }^{138}$.

These results suggest that under similar differentiation conditions as other stem and neuroprogenitor cell populations, human epSPCs rapidly express neuronal markers, but development of functionality likely requires greater time in culture by comparison, even relative to rodent correlates. Addition of NT3 to our cultures in future may aid in neuron maturation, as in the developing CNS, the action of BDNF on TrkB is followed by the actions of neurotrophin3 on the TrkC receptor, which has roles in differentiation and survival over longer periods ${ }^{154}$. Future work will need to determine at what point epSPC cells expressing $\beta I I I-t u b u l i n$ gain functional neuron properties, and whether epSPCs from healthy spinal cords differ from those harvested from injured donors in the time required for development of functionality.

Passive Membrane Properties Do Not Change With TIC

Overall RMP is significantly more hyperpolarized in FBS cultures than in $\mathrm{BDNF}+\mathrm{GDNF}+\mathrm{FBS}$, and more than BDNF+GDNF cells without reaching significance. However, despite this, RMP under each condition is more depolarized than typical mature neurons. These differences were not significantly affected by TIC, and from the earliest recording time points FBS cells were more hyperpolarized. In contrast to this, BDNF and GDNF displayed higher capacitances than those with serum alone from the earliest recordings, and these differences were not affected by TIC. This is not unexpected, given the well established role of growth factors in promoting extensive process growth ${ }^{96,100,109}$. Input resistance is not 
significantly different between or within conditions regardless of TIC. The capacitance increase in BDNF and GDNF cultures without consequent changes in input resistance suggest that while these growth factors promote process growth (and therefore more membrane channels), they are not functional. Further, development of lower input resistance values corresponds with a more hyperpolarized RMP in FBS and BDNF+GDNF cultures. This effect was not seen in cells in $\mathrm{BDNF}+\mathrm{GDNF}+\mathrm{FBS}$, which may indicate competing effects of the growth factors and serum. Indeed, in cultures of rat embryonic telencephalon neuroprogenitors, FBS was found to mask the actions of BDNF and isobutyl-1-methylxantine (IBMX) in differentiation and development of mature neuronal properties ${ }^{133}$.

The lack of a discernible pattern in development of stereotyped neuronal membrane properties indicates a heterogeneous group of immature cells at different developmental stages co-existing within a culture, regardless of exposure time to differentiation agents. This may be a result of the neurosphere assay itself, as cells at the core of the neurosphere typically differentiate quicker than those at the surface ${ }^{155}$. In conjunction with these electrophysiological properties, the extensive $\beta$ III-tubulin staining and almost complete lack of GFAP or O4 suggest the cultures begin the process of differentiation but remain immature, with different cells proceeding towards maturity at different rates, failing to achieve functionality even up to the $10^{\text {th }}$ week in culture. Whether epSPCs from uninjured spinal cords require longer incubations in the current concentrations of differentiation agents, or whether they simply will never develop action potential firing and network activity amongst themselves without inputs from pre-existing mature neuronal circuitry, is still to be elucidated. The latter is unlikely, as this would make them unique not only from their rodent counterparts ${ }^{58,67}$, but also from iPSCs ${ }^{139,149}$, hESCs $^{132,140,150,156-}$ ${ }^{158}$, and other NSCs ${ }^{133,134,138,159,160}$. Despite this, co-culture of epSPCs with mature astrocytes 
and/or neurons may be useful in future to expedite maturation. Indeed, neurons from human iPSCs co-cultured with either cell type achieved mature physiological neuronal characteristics significantly faster than when cultured alone ${ }^{161}$. As single and/or repetitive action potential firing has been found in large proportions of differentiated neurons from each of the aforementioned stem cell sources well before the 10 week mark, such a co-culture strategy will likely be useful in future.

As maturation of membrane excitability is a progressive sequence of changes in electrical properties ${ }^{162}$, tracking the development of these passive properties over longer time periods may be useful in predicting the timeline for development of mature neuronal signaling in differentiating epSPCs. Conversion of stem cells to neuron-like cells involves extensive membrane rearrangement, including ion channel insertion ${ }^{139}$. Development of rat motorneurons during gestation involves progressive hyperpolarization of membranes from $-53 \mathrm{mV}$ at gestational day 14 to $-62 \mathrm{mV}$ after birth. Capacitance increases from $27 \mathrm{pF}$ to $137 \mathrm{pF}$ over the same timeline, with input resistance decreasing from $271 \mathrm{M} \Omega$ to $65 \mathrm{M} \Omega^{162}$. Neurons differentiated from stem cells appear to have lower capacitances and higher input resistances, with varying levels based on stem cell source and differentiation media used. Those differentiated from hESCs show gradually hyperpolarizing RMPs from $-34 \mathrm{mV}$ at week 4 in culture to $-58 \mathrm{mV}$ at week 10 , with capacitance increasing from $17 \mathrm{pF}$ to $26 \mathrm{pF}$ and input resistance decreasing from $2.5 \mathrm{G} \Omega$ to $1.8 \mathrm{G} \Omega^{140}$. Neurons derived from iPSCs show relatively depolarized membranes at early in vitro time points, hovering around $-35 \mathrm{mV}$ between weeks 5 and 6. This quickly hyperpolarizes, however, and by the end of week 6 the average RMP is -49 $\mathrm{mV}$. Similar trends are seen in input resistance, decreasing from over $2.3 \mathrm{G} \Omega$ to just over 1.5 $\mathrm{G} \Omega^{149}$. While maturation occurred quicker than in our epSPC cultures, the trend of gradually 
hyperpolarizing membranes, capacitances from $10-40 \mathrm{pF}$, and $\mathrm{G} \Omega$ input resistance values regardless of TIC is the same.

After 2 weeks in culture, differentiated neurons from SVZ NSCs show capacitance values ranging from $19.1 \mathrm{pF}$ in adult to $23 \mathrm{pF}$ in aged and embryonic cultures, with high input resistances (approximately $2 \mathrm{G} \Omega$ ) regardless of donor animal age. Mean RMP is consistently more hyperpolarized than $-60 \mathrm{mV}^{138}$. After 1-2 weeks in differentiation media, hippocampal NSCs show RMPs of $-59 \mathrm{mV}$ (down from $-88 \mathrm{mV}$ in undifferentiated), capacitances of $22 \mathrm{pF}$ (up from $11 \mathrm{pF}$ ) and input resistances of $770 \mathrm{M} \Omega$ (up from $121 \mathrm{M} \Omega)^{134}$. Human NSCs differentiated to glutamatergic neurons show progressive hyperpolarization of RMP from week $5(-31 \mathrm{mV})$ to week $9(-56 \mathrm{mV})$ in culture ${ }^{152}$. Prior to development of mature granule cell properties, intermediate stage immature neurons derived from this NSC population show input resistances around $4 \mathrm{G} \Omega^{163}$. Human fibroblast-derived iPSCs differentiated to action potential-firing neurons show input resistance values above $1 \mathrm{G} \Omega$, capacitances above $33 \mathrm{pF}$, and RMPs around -42 $\mathrm{mV}^{139}$. These values are similar to these seen in our cultures and lends credence to the idea that epSPCs require longer incubation in differentiation media to develop membrane excitability, with our results reflecting an immature cell population en route to developing features of mature neurons.

Passive Membrane Properties Indicate Early Stages of Neuron Differentiation

As our neurosphere assay only used 1-2 passages, cultures may have contained undifferentiated epSPCs, tanycytes, and/or astrocytes. Our selection criteria may have biased the results towards characterizing one of these cell types. However, this is unlikely given the electrophysiological properties of our cells. Mean RMP across all culture conditions ranged from 
$-20.91 \pm 2.81 \mathrm{mV}$ to $-34.72 \pm 3.37 \mathrm{mV}$; mean capacitance ranged from $9.10 \pm 1.48 \mathrm{pF}$ to $28.42 \pm$ $3.70 \mathrm{pF}$; and mean input resistance ranged from $0.91 \pm 0.10 \mathrm{G} \Omega$ to $1.23 \pm 0.18 \mathrm{G} \Omega$. While the observed RMP range does not fit that seen in mature neurons $\left(-40 \mathrm{mV}\right.$ to $\left.-90 \mathrm{mV}^{135-137}\right)$, it is far more depolarized than any of the aforementioned potential contaminant cell sources. Undifferentiated rat ependymal cells and tanycytes have extensively hyperpolarized membranes typical of astrocytes, with RMPs of $-79.9 \mathrm{mV}$ and $-79.5 \mathrm{mV}$ respectively ${ }^{164}$. RGs from turtle cortices have RMPs in the range of $-90 \mathrm{mV}^{165}$, while epSPCs from the rat central canal typically feature values between $-76 \mathrm{mV}$ and $-84 \mathrm{mV}^{37}$. RMP differs only slightly between epSPCs in the lateral central canal and those at the dorsal and ventral poles, with average values around $-84 \mathrm{mV}$ and $-82 \mathrm{mV}$ respectively ${ }^{37}$. Further, ependymal cells have extremely low input resistances, ranging from $<1 \mathrm{M} \Omega$ in the cortex ${ }^{164}$ to $361 \mathrm{M} \Omega$ in the central canal $^{37}$, as a result of extensive gap junction coupling ${ }^{58,165}$. This contrasts the high Rn values observed in our cultures. It is therefore apparent that the cells recorded from in our study have undergone morphological and electrical changes from the original undifferentiated epSPC state.

Our cells are likely not astrocyte derived either, given the significantly hyperpolarized RMP and low Rn of astrocytes relative to that observed in our cultures, as well as their tendency to be extensively coupled via gap junctions. Mature astrocyte RMP is typically around $-84 \mathrm{mV}$, varying based on CNS location. Neonatal astrocytes are slightly more hyperpolarized than those in adults (-85 mV vs. $-80 \mathrm{mV}$, respectively $)^{164,166-170}$. Proliferating astrocytes become more depolarized, with RMPs around $-53 \mathrm{mV}^{167}$, while reactive astrocytes induced by lesion injury have values from $-80 \mathrm{mV}$ to $-87 \mathrm{mV}^{168}$. Uninjured, proliferating and reactive astrocytes have capacitances from $16 \mathrm{pF}$ to $59 \mathrm{pF}^{167,168}$, while mature adult astrocytes have low Rns from $2 \mathrm{M} \Omega$ to $40 \mathrm{M} \Omega^{164,169-171}$. Astrocytes, like ependymal cells, display extensive gap junction coupling in 
vivo and in vitro ${ }^{166,170,172}$, with low input resistances ${ }^{169}$. While our cells show capacitance values in the range displayed by astrocytes, the relatively depolarized RMP, high input resistance and lack of GFAP expression make an astrocytic fate unlikely.

\section{The Majority of BIII-Tubulin Cells Exhibit Synaptic Responses}

Over $80 \%$ of cells healthy enough to undergo voltage clamp protocols exhibited spontaneous postsynaptic currents, regardless of culture condition. This is indicative of differentiation, as ependymal cells have no intrinsic excitability and exhibit no synaptic potentials ${ }^{165}$. The presence of these events is surprising given the lack of action potentials, as it is expected that action potential firing would precede synaptic inputs. Indeed, in cultures of hESC derived neurons, single action potential spikes were first observed at week 4 in differentiation media, with the first evidence of synaptic activity appearing at week $5^{151}$. In differentiation cultures of rodent NSCs, $50 \%$ of neurons fire action potentials within 7 days. However, only $16.7 \%$ and $5 \%$ of cells in IBMX and BDNF differentiation conditions, respectively, show spontaneous synaptic activity ${ }^{133}$. Gunhanlar et al (2018) observed spontaneous synaptic events at a holding potential of $-80 \mathrm{mV}$ in electrically mature neurons from human iPSCs, with amplitudes of $16 \mathrm{pA}$ and a decay time of $5.6 \mathrm{~ms}$. The authors attribute these events to AMPA and NMDA receptor kinetics ${ }^{173}$.

The events observed in our study are similarly low amplitude with rapid decay times. At a holding potential of $-60 \mathrm{mV}$, amplitudes of the observed currents were consistently between -5 and $-10 \mathrm{pA}$, with decay constants between 10 and $15 \mathrm{~ms}$. At $+60 \mathrm{mV}$, event amplitudes increase to between 10 and $20 \mathrm{pA}$ with decay times between 15 and $20 \mathrm{~ms}$. When event amplitude was plotted at each recorded voltage, a reversal potential close to $0 \mathrm{mV}$ was noted. This is indicative 
of non-selection cationic permeable receptors. Indeed, AMPA and NMDA receptors have reversal potentials close to $0 \mathrm{mV}$, and always produce excitatory postsynaptic responses ${ }^{137}$. The events at $-60 \mathrm{mV}$ likely represent AMPA receptors and those at +60 mV NMDA receptors, as large depolarizations are required to remove the $\mathrm{Mg}^{2+}$ block from NMDA receptors ${ }^{174}$. Fast glutamate neurotransmission activates NMDA and AMPA receptors in the postsynaptic cell, with AMPA receptor firing significantly faster than NMDA receptors ${ }^{175}$. Fast glutamatergic signaling through AMPA receptors typically shows decay constants between $1-5 \mathrm{~ms}^{176}$. The deactivation time course of NMDA receptors is based on the combination of its constituent subunits: NR1 in combination with varying levels of NR2A, B, C or D. The presence of the NR2B subunit significantly increases decay time, while receptors containing NR2A fire significantly faster. Indeed, without NR2B decay times range from $19-45 \mathrm{~ms}^{176,177}$, whereas NR1:NR2B glutamate receptors typically have decay constants around $71 \mathrm{~ms}$, rising as NR2B levels increase ${ }^{177}$. Our data appears to be consistent with excitatory glutamatergic responses, with some mediated by NMDA receptors given the observed outward rectification and slower kinetics at positive holding potentials. The rapid decay constant is consistent with high levels of the NR2A subunit, however further electrophysiological and immunocytochemical studies are needed to confirm this.

Anderson et al (2015) noted similar spontaneous excitatory postsynaptic currents prior to development of action potentials in neurons differentiated from human neural progenitor cells of the developing embryonic cortex. These events were evident at $-70 \mathrm{mV}$ and $+40 \mathrm{mV}$ holding potentials, with fast decay times and consistent amplitudes around $10 \mathrm{pA}$. As in our study, they observed no spontaneous currents at a holding of $0 \mathrm{mV}$, indicating the lack of functional inhibitory synapses. Concurrent increases in expression levels of AMPA and NMDA receptor 
subunits lead to the conclusion that these events were the result of glutamate signaling, and that the generation of these potentials was consistent with differentiation towards a predominantly excitatory glutamatergic neuron fate ${ }^{159}$. While our data appear to fit with AMPA and/or NMDA receptor signaling, future studies will look to concretely identify the receptors responsible for these spontaneous potentials through the blocking of excitatory postsynaptic currents via specific antagonists, activating channels through the introduction of specific agonists, and immunocytochemical detection of specific receptor subtypes.

The observed events were voltage dependent, with greater amplitude at $+60 \mathrm{mV}$ than at $60 \mathrm{mV}$, indicative of either outward rectification or a positive reversal potential. Event amplitude did not differ over time in culture, however in cultures containing BDNF and GDNF, $+60 \mathrm{mV}$ event decay time appeared to decrease. This is in keeping with AMPA and NMDA receptor maturation, as a significant acceleration in decay kinetics is observed as synapses mature ${ }^{178}$. This may also indicate a switch to a more AMPA receptor-dominated synapse ${ }^{178}$. Future studies will need to be undertaken to better characterize the signaling factors involved. Neurons from hESCs show significantly greater $-60 \mathrm{mV}$ spontaneous event amplitude at later time points, increasing from 5-6 pA at week 5 to $11-12 \mathrm{pA}$ at week 6 of differentiation ${ }^{151}$. In keeping with a potential competition in the differentiation effects of FBS and BDNF, BDNF+GDNF+FBS cultures showed significantly lower amplitude events at later time points $(11.56 \mathrm{pA}$ at weeks $7+$ compared to $16.46 \mathrm{pA}$ at weeks 2-6). Aside from this difference, no change in event amplitude was noted over time. This may be a result of recordings from cells at different stages of differentiation regardless of TIC, or a consistent end state. Future studies will identify the major receptors involved in neurons derived from epSPCs, both immunocytochemically and electrophysiologically using specific channel blockers. 


\section{Conclusions and Future Directions}

Determining the time required for differentiating epSPCs to develop action potential firing is a key next step, as no recorded cells differentiated from epSPCs displayed action potential firing. Co-culturing with astrocytes or mature primary neurons may speed this process along. However, cell health and long-term viability represent a significant hurdle, as low success in achieving whole-cell patch clamping may bias recordings towards certain immature cell types. To that end, future studies will look into alternative media specifically designed for primary cell cultures. Early literature has found that BrainPhys neuronal media from StemCell Technologies promotes synaptic activity, neuron differentiation, and cell health of primary human stem cells over the long term, with cultures lasting up to 18 weeks ${ }^{179,180}$. Further, the criteria used for cell selection may be biasing for cells at certain developmental stages. Most of the culture forms diffuse networks of cells regardless of seeding density, with no discernible membrane or processes, and no identifiable individual cells. Within this population may be networks of mature neurons unable to be visualized using light microscopy. Future studies will look at ways to better characterize these by immunocytochemically identifying synapses, neurotransmitter-specific enzymes, NSC and neural progenitor presence, number of glia at different culture time points, and proportion of neurons expressing mature markers. Cell counts for the above markers on FBS, $\mathrm{BDNF}+\mathrm{GDNF}$ and $\mathrm{BDNF}+\mathrm{GDNF}+\mathrm{FBS}$ cultures are currently underway, and will be extended beyond week 2 to elucidate whether the majority cell fate changes over time. In terms of electrophysiological characterization, using NMDA and AMPA blockers to determine whether the observed spontaneous, voltage-dependent currents are indeed glutamate-based is an immediate next step. 
Despite not achieving functionality within the culture timeframe, the unique neuronal fate preference of human epSPCs relative to rodents is an exciting finding with implications in the potential application of this stem cell pool to treating CNS injury. 


\section{References}

1. Rowland, J. W., Hawryluk, G. W. J., Kwon, B. \& Fehlings, M. G. Current status of acute spinal cord injury pathophysiology and emerging therapies: promise on the horizon.

Neurosurg. Focus 25, E2 (2008).

2. Oyinbo, C. A. Secondary injury mechanisms in traumatic spinal cord injury: A nugget of this multiply cascade. Acta Neurobiol. Exp. (Wars). 71, 281-299 (2011).

3. Thuret, S., Moon, L. D. F. \& Gage, F. H. Therapeutic interventions after spinal cord injury. Nat. Rev. Neurosci. 7, 628-643 (2006).

4. $\quad$ Kirke Rogers, W. \& Todd, M. Acute spinal cord injury. Best Pract. Res. Clin. Anaesthesiol. 30, 27-39 (2016).

5. Y1lmaz, T. Pathophysiology of the spinal cord injury. J. Clin. Exp. Investig. 5, 131-136 (2014).

6. Lee, J. \& Thumbikat, P. Pathophysiology, presentation and management of spinal cord injury. Surg. (United Kingdom) 33, 238-247 (2015).

7. Kjell, J. \& Olson, L. Rat models of spinal cord injury: from pathology to potential therapies. Dis. Model. Mech. 9, 1125-1137 (2016).

8. Hulsebosch, C. E. Recent Advances in Pathophysiology and Treatment of Spinal Cord Injury. Adv. Physiol. Educ. 26, 238-255 (2002).

9. Mataliotakis, G. I. \& Tsirikos, A. I. Spinal cord trauma: pathophysiology, classification of spinal cord injury syndromes, treatment principles and controversies. Orthop. Trauma 30, 440-449 (2016).

10. Duan, H. et al. Endogenous neurogenesis in adult mammals after spinal cord injury. Sci. China Life Sci. 59, 1313-1318 (2016).

11. McDonough, A. \& Martínez-Cerdeño, V. Endogenous proliferation after spinal cord injury in animal models. Stem Cells Int. 2012, (2012).

12. Braakman, R. Mechanism and pathophysiology of spinal and spinal cord injury. Neurocirugia 2, 232-244 (1991).

13. Grossman, S. D., Rosenberg, L. J. \& Wrathall, J. R. Temporal-spatial pattern of acute neuronal and glial loss after spinal cord contusion. Exp. Neurol. 168, 273-282 (2001).

14. Schwab, J. M., Zhang, Y., Kopp, M. A., Brommer, B. \& Popovich, P. G. The paradox of chronic neuroinflammation, systemic immune suppression, autoimmunity after traumatic chronic spinal cord injury. Exp. Neurol. 258, 121-129 (2014).

15. Silva, N. A., Sousa, N., Reis, R. L. \& Salgado, A. J. From basics to clinical: A comprehensive review on spinal cord injury. Prog. Neurobiol. 114, 25-57 (2014). 
16. Yuan, Y.-M. \& He, C. The glial scar in spinal cord injury and repair. Neurosci. Bull. 29, 421-435 (2013).

17. Ramer, L. M., Ramer, M. S. \& Bradbury, E. J. Restoring function after spinal cord injury: Towards clinical translation of experimental strategies. Lancet Neurol. 13, 1241-1256 (2014).

18. Varma, A. K. et al. Spinal Cord Injury: A Review of Current Therapy, Future Treatments, and Basic Science Frontiers. Neurochem. Res. 38, 895-905 (2013).

19. Barreiro-Iglesias, A. Targeting ependymal stem cells in vivo as a non-invasive therapy for spinal cord injury. Dis. Model. Mech. 3, 667-668 (2010).

20. Hamilton, L. K., Truong, M. K. V, Bednarczyk, M. R., Aumont, A. \& Fernandes, K. J. L. Cellular organization of the central canal ependymal zone, a niche of latent neural stem cells in the adult mammalian spinal cord. Neuroscience 164, 1044-1056 (2009).

21. Altman, J. \& Bayer, S. A. The development of the rat spinal cord. Adv. Anat. Embryol. Cell Biol. 85, 1-164 (1984).

22. Panayiotou, E. \& Malas, S. Adult spinal cord ependymal layer: a promising pool of quiescent stem cells to treat spinal cord injury. Front. Physiol. 4, 3-5 (2013).

23. Lacroix, S. et al. Central canal ependymal cells proliferate extensively in response to traumatic spinal cord injury but not demyelinating lesions. PLoS One 9, (2014).

24. Spassky, N. Adult Ependymal Cells Are Postmitotic and Are Derived from Radial Glial Cells during Embryogenesis. J. Neurosci. 25, 10-18 (2005).

25. Qin, Y., Zhang, W. \& Yang, P. Current states of endogenous stem cells in adult spinal cord. J. Neurosci. Res. 93, 391-398 (2015).

26. Liu, Y. et al. Endogenous neural stem cells in central canal of adult rats acquired limited ability to differentiate into neurons following mild spinal cord injury. Int. J. Clin. Exp. Pathol. 8, 3835-3842 (2015).

27. Sturrock, R. R. An electron microscopic study of the development of the ependyma of the central canal of the mouse spinal cord. J. Anat. 132, 119-36 (1981).

28. Bruni, J. E. Ependymal development, proliferation, and functions: A review. Microsc. Res. Tech. 41, 2-13 (1998).

29. Cawsey, T., Duflou, J., Shannon Weickert, C. \& Gorrie, C. A. Nestin-Positive Ependymal Cells Are Increased in the Human Spinal Cord after Traumatic Central Nervous System Injury. J. Neurotrauma 1402, 150515094428007 (2015).

30. Cramer, G. D., Darby, S. A. \& Cramer, G. D. Clinical anatomy of the spine, spinal cord, and $A N S$. (Elsevier Health Sciences, 2014).

31. Yasui, K., Hashizume, Y., Yoshida, M., Kameyama, T. \& Sobue, G. Age-related morphologic changes of the central canal of the human spinal cord. Acta Neuropathol. 97, 
253-259 (1999).

32. Moore, K. L., Persaud, T. V. N. \& Torchia, M. G. The developing human : clinically oriented embryology.

33. Saker, E. et al. The Human Central Canal of the Spinal Cord: A Comprehensive Review of its Anatomy, Embryology, Molecular Development, Variants, and Pathology. Cureus 8, (2016).

34. Dromard, C. et al. Adult human spinal cord harbors neural precursor cells that generate neurons and glial cells in vitro. J. Neurosci. Res. 86, 1916-1926 (2008).

35. Meletis, K. et al. Spinal cord injury reveals multilineage differentiation of ependymal cells. PLoS Biol. 6, 1494-1507 (2008).

36. Sabelström, H., Stenudd, M. \& Frisén, J. Neural stem cells in the adult spinal cord. Exp. Neurol. 260, 44-49 (2014).

37. Corns, L. F., Deuchars, J. \& Deuchars, S. A. GABAergic responses of mammalian ependymal cells in the central canal neurogenic niche of the postnatal spinal cord. Neurosci. Lett. 553, 57-62 (2013).

38. Williams, B. THE DISTENDING FORCE IN THE PRODUCTION OF COMMUNICATING SYRINGOMYELIA. Lancet 296, 41-42 (1970).

39. Becker, D. P., Wilson, J. A. \& Watson, G. W. The spinal cord central canal: response to experimental hydrocephalus and canal occlusion. J. Neurosurg. 36, 416-424 (1972).

40. Newman, P. K., Terenty, T. R. \& Foster, J. B. Some observations on the pathogenesis of syringomyelia. J. Neurol. Neurosurg. Psychiatry 44, 964-9 (1981).

41. Watson, C., Paxinos, G., Kayalioglu, G. \& Christopher \& Dana Reeve Foundation. The spinal cord: a Christopher and Dana Reeve Foundation text and atlas.

(Elsevier/Academic Press, 2009).

42. Storer, K. P., Toh, J., Stoodley, M. A. \& Jones, N. R. The central canal of the human spinal cord: A computerised 3-D study. J. Anat. 192, 565-572 (1998).

43. Choi, B. H., Kim, R. C., Suzuki, M. \& Choe, W. The ventriculus terminalis and filum terminale of the human spinal cord. Hum. Pathol. 23, 916-20 (1992).

44. Lendon, R. G. \& Emery, J. L. Forking of the central canal in the equinal cord of children. J. Anat. 106, 499-505 (1970).

45. Hugnot, J. P. \& Franzen, R. The spinal cord ependymal region: a stem cell niche in the caudal central nervous system. Front. Biosci. (Landmark Ed. 16, 1044-59 (2011).

46. SATO, K., KUBOTA, T., ISHIDA, M. \& HANDA, Y. Spinal Tanycytic Ependymoma With Hematomyelia. Neurol. Med. Chir. (Tokyo). 45, 168-171 (2005).

47. Roessmann, U., Velasco, M. E., Sindely, S. D. \& Gambetti, P. Glial fibrillary acidic 
protein (GFAP) in ependymal cells during development. An immunocytochemical study. Brain Res. 200, 13-21 (1980).

48. Marichal, N., Garcia, G., Radmilovich, M., Trujillo-Cenoz, O. \& Russo, R. E. Enigmatic Central Canal Contacting Cells: Immature Neurons in 'Standby Mode'? J. Neurosci. 29, 10010-10024 (2009).

49. Stoeckel, M.-E. et al. Cerebrospinal fluid-contacting neurons in the rat spinal cord, a ?aminobutyric acidergic system expressing the P2X2 subunit of purinergic receptors, PSANCAM, and GAP-43 immunoreactivities: Light and electron microscopic study. J. Comp. Neurol. 457, 159-174 (2003).

50. Vigh, B. \& Vigh-Teichmann, I. Actual problems of the cerebrospinal fluid-contacting neurons. Microsc. Res. Tech. 41, 57-83 (1998).

51. Galvão, RP, Garcea-Verdugo, JM, Alvarez-Buylla, A. Brain-derived neurotrophic factor signaling does not stimulate subventricular zone neurogenesis in adult mice and rats. $J$. ... 28, 13368-13383 (2008).

52. Barnabé-Heider, F. \& Miller, F. D. Endogenously produced neurotrophins regulate survival and differentiation of cortical progenitors via distinct signaling pathways. $J$. Neurosci. 23, 5149-60 (2003).

53. Klein, R. et al. The trkB tyrosine protein kinase is a receptor for brain-derived neurotrophic factor and neurotrophin-3. Cell 66, 395-403 (1991).

54. Koo, H. \& Choi, B. H. Expression of glial cell line-derived neurotrophic factor (GDNF) in the developing human fetal brain. Int. J. Dev. Neurosci. 19, 549-558 (2001).

55. Pacey, L., Stead, S., Gleave, J., Tomczyk, K. \& Doering, L. Neural Stem Cell Culture: Neurosphere generation, microscopical analysis and cryopreservation. Protoc. Exch. (2006). doi:10.1038/nprot.2006.215

56. Reynolds, B. A. \& Rietze, R. L. Neural stem cells and neurospheres-re-evaluating the relationship. Nat. Methods 2, 333-336 (2005).

57. Barnabé-Heider, F. et al. Origin of new glial cells in intact and injured adult spinal cord. Cell Stem Cell 7, 470-482 (2010).

58. Marichal, N., García, G., Radmilovich, M., Trujillo-Cenóz, O. \& Russo, R. E. Spatial Domains of Progenitor-Like Cells and Functional Complexity of a Stem Cell Niche in the Neonatal Rat Spinal Cord. Stem Cells 30, 2020-2031 (2012).

59. Shihabuddin, L. S., Horner, P. J., Ray, J. \& Gage, F. H. Adult spinal cord stem cells generate neurons after transplantation in the adult dentate gyrus. $J$. Neurosci. 20, 8727-35 (2000).

60. Li, X. et al. Regenerative Potential of Ependymal Cells for Spinal Cord Injuries Over Time. EBioMedicine 13, 55-65 (2016). 
61. Bernal, G. M. \& Peterson, D. A. Phenotypic and gene expression modification with normal brain aging in GFAP-positive astrocytes and neural stem cells. Aging Cell 10, 466-482 (2011).

62. Lin, D.-T. et al. Ca2+ signaling, mitochondria and sensitivity to oxidative stress in aging astrocytes. Neurobiol. Aging 28, 99-111 (2007).

63. Zhang, S. \& Cui, W. Sox2, a key factor in the regulation of pluripotency and neural differentiation. World J. Stem Cells 6, 305-11 (2014).

64. Del Barrio, M. G. et al. A regulatory network involving Foxn4, Mash1 and delta-like 4/Notch1 generates V2a and V2b spinal interneurons from a common progenitor pool. Development 134, 3427-3436 (2007).

65. Takahashi, M., Arai, Y., Kurosawa, H., Sueyoshi, N. \& Shirai, S. Ependymal cell reactions in spinal cord segments after compression injury in adult rat. J. Neuropathol. Exp. Neurol. 62, 185-194 (2003).

66. Barone BM., E. A. R. Ependymomas. A clinical survey. J. Neurosurg. 33, 428-438 (1970).

67. Moreno-Manzano, V. et al. Activated spinal cord ependymal stem cells rescue neurological function. Stem Cells 27, 733-743 (2009).

68. Lytle, J. M. \& Wrathall, J. R. Glial cell loss, proliferation and replacement in the contused murine spinal cord. Eur. J. Neurosci. 25, 1711-1724 (2007).

69. Zai, L. J. \& Wrathall, J. R. Cell proliferation and replacement following contusive spinal cord injury. Glia 50, 247-257 (2005).

70. Bruni, J. E. \& Anderson, W. A. Ependyma of the Rat Fourth Ventricle and Central Canal: Response to Injury. Cells Tissues Organs 128, 265-273 (1987).

71. Horky, L. L., Galimi, F., Gage, F. H. \& Horner, P. J. NIH Public Access. October 498, 525-538 (2008).

72. Sabelström, H. et al. Resident neural stem cells restrict tissue damage and neuronal loss after spinal cord injury in mice. Science (80-. ). 342, 637-640 (2013).

73. Hofstetter, C. P. et al. Allodynia limits the usefulness of intraspinal neural stem cell grafts; directed differentiation improves outcome. Nat. Neurosci. 8, 346-353 (2005).

74. Brazelton, T. R., M. V. Rossi, F., L. Keshet, G. \& M. Blau, H. From Marrow to Brain: Expression of Neuronal. Sci. 290 53, 1775-1033 (2000).

75. Gritti, A. et al. Multipotential stem cells from the adult mouse brain proliferate and selfrenew in response to basic fibroblast growth factor. J. Neurosci. 16, 1091-100 (1996).

76. Palmer, T. D., Markakis, E. A., Willhoite, A. R., Safar, F. \& Gage, F. H. Fibroblast growth factor-2 activates a latent neurogenic program in neural stem cells from diverse regions of the adult CNS. J. Neurosci. 19, 8487-97 (1999). 
77. Kojima, A. \& Tator, C. H. Intrathecal Administration of Epidermal Growth Factor and Fibroblast Growth Factor 2 Promotes Ependymal Proliferation and Functional Recovery after Spinal Cord Injury in Adult Rats. J. Neurotrauma 19, 223-238 (2002).

78. Mothe, A. J., Zahir, T., Santaguida, C., Cook, D. \& Tator, C. H. Neural stem/progenitor cells from the adult human spinal cord are multipotent and self-renewing and differentiate after transplantation. PLoS One 6, (2011).

79. Snethen, H., Love, S. \& Scolding, N. Disease-responsive neural precursor cells are present in multiple sclerosis lesions. Regen. Med. 3, 835-847 (2008).

80. Sakakibara, A., Aoki, E., Hashizume, Y., Mori, N. \& Nakayama, A. Distribution of nestin and other stem cell-related molecules in developing and diseased human spinal cord. Pathol. Int. 57, 358-368 (2007).

81. Takano, T. \& Becker, L. E. Overexpression of nestin and vimentin in the ependyma of spinal cords from hydrocephalic infants. Neuropathol. Appl. Neurobiol. 23, 3-15 (1997).

82. Uchida, Y., Nakano, S., Gomi, F. \& Takahashi, H. Differential regulation of basic helixloop-helix factors Mash1 and Olig2 by beta-amyloid accelerates both differentiation and death of cultured neural stem/progenitor cells. J. Biol. Chem. 282, 19700-9 (2007).

83. Kallur, T., Gisler, R., Lindvall, O. \& Kokaia, Z. Pax6 promotes neurogenesis in human neural stem cells. Mol. Cell. Neurosci. 38, 616-628 (2008).

84. Martens, D. J., Seaberg, R. M. \& Van Der Kooy, D. In vivo infusions of exogenous growth factors into the fourth ventricle of the adult mouse brain increase the proliferation of neural progenitors around the fourth ventricle and the central canal of the spinal cord. Eur. J. Neurosci. 16, 1045-1057 (2002).

85. Du, J. et al. Transfection of the glial cell line-derived neurotrophic factor gene promotes neuronal differentiation. Neural Regen. Res. 9, 33-40 (2014).

86. Lu, P. et al. Long-distance growth and connectivity of neural stem cells after severe spinal cord injury. Cell 150, 1264-1273 (2012).

87. Parr, A. M. et al. Transplanted adult spinal cord-derived neural stem/progenitor cells promote early functional recovery after rat spinal cord injury. Neuroscience 155, 760-770 (2008).

88. Tamm, C., Galitó, S. P. \& Annerén, C. A comparative study of protocols for mouse embryonic stem cell culturing. PLoS One 8, 1-10 (2013).

89. Hung, C. H. \& Young, T. H. Differences in the effect on neural stem cells of fetal bovine serum in substrate-coated and soluble form. Biomaterials 27, 5901-5908 (2006).

90. Lee, K. Conditions and Techniques for Mouse Embryonic Stem Cell Derivation and Culture. Embryonic Stem Cells - Basic Biol. to Bioeng. 86-115 (2011). doi:10.5772/55105

91. Kwon, D. et al. The effect of fetal bovine serum (FBS) on efficacy of cellular 
reprogramming for induced pluripotent stem cell (iPSC) generation. Cell Transplant. 25, 1025-1042 (2016).

92. Bettiol, E. et al. Fetal bovine serum enables cardiac differentiation of human embryonic stem cells. Differentiation 75, 669-681 (2007).

93. Lee, M.-S. et al. Enhanced Cell Growth of Adipocyte-Derived Mesenchymal Stem Cells Using Chemically-Defined Serum-Free Media. Int. J. Mol. Sci. 18, 1779 (2017).

94. Sandhya, V. K. et al. A network map of BDNF/TRKB and BDNF/p75NTR signaling system. J. Cell Commun. Signal. 7, 301-307 (2013).

95. Murray, P. S. \& Holmes, P. V. An overview of brain-derived neurotrophic factor and implications for excitotoxic vulnerability in the hippocampus. Int. J. Pept. 2011, (2011).

96. Chen, B.-Y. et al. Brain-derived neurotrophic factor stimulates proliferation and differentiation of neural stem cells, possibly by triggering the $\mathrm{Wnt} / \beta$-catenin signaling pathway. J. Neurosci. Res. 41, n/a-n/a (2012).

97. Lim, J. Y. et al. Brain-derived neurotrophic factor stimulates the neural differentiation of human umbilical cord blood-derived mesenchymal stem cells and survival of differentiated cells through MAPK/ERK and PI3K/Akt-dependent signaling pathways. $J$. Neurosci. Res. 86, 2168-2178 (2008).

98. Hyman, C. et al. BDNF is a neurotrophic factor for dopaminergic neurons of the substantia nigra. Nature 350, 230-232 (1991).

99. Yu, J. H. et al. GABAergic neuronal differentiation induced by brain-derived neurotrophic factor in human mesenchymal stem cells. Animal Cells Syst. (Seoul). 18, 17-24 (2014).

100. Kramár, E. A. et al. BDNF upregulation rescues synaptic plasticity in middle-aged ovariectomized rats. Neurobiol. Aging 33, 708-719 (2012).

101. Pencea, V., Bingaman, K. D., Wiegand, S. J. \& Luskin, M. B. Infusion of brain-derived neurotrophic factor into the lateral ventricle of the adult rat leads to new neurons in the parenchyma of the striatum, septum, thalamus, and hypothalamus. J. Neurosci. 21, 670617 (2001).

102. Scharfman, H. et al. Increased neurogenesis and the ectopic granule cells after intrahippocampal BDNF infusion in adult rats. Exp. Neurol. 192, 348-356 (2005).

103. Danzer, S. C., Crooks, K. R. C., Lo, D. C. \& McNamara, J. O. Increased expression of brain-derived neurotrophic factor induces formation of basal dendrites and axonal branching in dentate granule cells in hippocampal explant cultures. J. Neurosci. 22, 975463 (2002).

104. Islam, O., Loo, T. \& Heese, K. Brain-Derived Neurotrophic Factor (BDNF) has Proliferative Effects on Neural Stem Cells through the Truncated TRK-B Receptor, MAP Kinase, AKT, and STAT-3 Signaling Pathways. Curr. Neurovasc. Res. 6, 42-53 (2009). 
105. Prakash, N. \& Wurst, W. A Wnt signal regulates stem cell fate and differentiation in vivo. Neurodegener. Dis. 4, 333-8 (2007).

106. Jin, C., Samuelson, L., Cui, C.-B., Sun, Y. \& Gerber, D. A. MAPK/ERK and Wnt/ $\beta$ Catenin pathways are synergistically involved in proliferation of Sca-1 positive hepatic progenitor cells. Biochem. Biophys. Res. Commun. 409, 803-807 (2011).

107. Perry, J. M. et al. Cooperation between both Wnt/\{beta\}-catenin and PTEN/PI3K/Akt signaling promotes primitive hematopoietic stem cell self-renewal and expansion. Genes Dev. 25, 1928-42 (2011).

108. Ahmed, S., Reynolds, B. a \& Weiss, S. BDNF enhances the differentiation but not the survival of CNS stem cell-derived neuronal precursors. J. Neurosci. 15, 5765-5778 (1995).

109. Jiao, Y. et al. BDNF Increases Survival and Neuronal Differentiation of Human Neural Precursor Cells Cotransplanted with a Nanofiber Gel to the Auditory Nerve in a Rat Model of Neuronal Damage. Biomed Res. Int. 2014, (2014).

110. Tsai, L.-H., Delalle, I., Caviness, V. S., Chae, T. \& Harlow, E. p35 is a neural-specific regulatory subunit of cyclin-dependent kinase 5. Nature 371, 419-423 (1994).

111. Lian, D. et al. Exogenous BDNF increases neurogenesis in the hippocampus in experimental Streptococcus pneumoniae meningitis. J. Neuroimmunol. 294, 46-55 (2016).

112. Douglas-Escobar, M., Rossignol, C., Steindler, D., Zheng, T. \& Weiss, M. D. Neurotrophin-Induced Migration and Neuronal Differentiation of Multipotent Astrocytic Stem Cells In Vitro. PLoS One 7, 1-8 (2012).

113. Babu, H., Ramirez-Rodriguez, G., Fabel, K., Bischofberger, J. \& Kempermann, G. Synaptic network activity induces neuronal differentiation of adult hippocampal precursor cells through BDNF signaling. Front. Neurosci. 3, 1-11 (2009).

114. Chmielnicki, E. Adenovirally Expressed Noggin and Brain-Derived Neurotrophic Factor Cooperate to Induce New Medium Spiny Neurons from Resident Progenitor Cells in the Adult Striatal Ventricular Zone. J. Neurosci. 24, 2133-2142 (2004).

115. Maxwell, G. D., Reid, K., Elefanty, A., Bartlett, P. F. \& Murphy, M. Glial cell linederived neurotrophic factor promotes the development of adrenergic neurons in mouse neural crest cultures. Proc. Natl. Acad. Sci. U. S. A. 93, 13274-9 (1996).

116. Airaksinen, M. S. \& Saarma, M. The GDNF family: Signalling, biological functions and therapeutic value. Nat. Rev. Neurosci. 3, 383-394 (2002).

117. Oatley, J. M., Avarbock, M. R., Telaranta, A. I., Fearon, D. T. \& Brinster, R. L. Identifying genes important for spermatogonial stem cell self-renewal and survival. Proc. Natl. Acad. Sci. U. S. A. 103, 9524-9 (2006).

118. Huang, L., Guo, H., Hellard, D. T. \& Katz, D. M. Glial cell line-derived neurotrophic factor (GDNF) is required for differentiation of pontine noradrenergic neurons and 
patterning of central respiratory output. Neuroscience 130, 95-105 (2005).

119. Ostenfeld, T. et al. Neurospheres modified to produce glial cell line-derived neurotrophic factor increase the survival of transplanted dopamine neurons. J. Neurosci. Res. 69, 955965 (2002).

120. Wang, F. et al. GDNF-pretreatment enhances the survival of neural stem cells following transplantation in a rat model of Parkinson's disease. Neurosci. Res. 71, 92-98 (2011).

121. Xiao, H., Hirata, Y., Isobe, K. \& Kiuchi, K. Glial cell line-derived neurotrophic factor upregulates the expression of tyrosine hydroxylase gene in human neuroblastoma cell lines. J. Neurochem. 82, 801-808 (2002).

122. Theofilopoulos, S. et al. Parallel induction of the formation of dopamine and its metabolites with induction of tyrosine hydroxylase expression in foetal rat and human cerebral cortical cells by brain-derived neurotrophic factor and glial-cell derived neurotrophic factor. Dev. Brain Res. 127, 111-122 (2001).

123. Chen, Y., Ai, Y., Slevin, J. R., Maley, B. E. \& Gash, D. M. Progenitor proliferation in the adult hippocampus and substantia nigra induced by glial cell line-derived neurotrophic factor. Exp. Neurol. 196, 87-95 (2005).

124. Boku, S. et al. GDNF facilitates differentiation of the adult dentate gyrus-derived neural precursor cells into astrocytes via STAT3. Biochem. Biophys. Res. Commun. 434, 779784 (2013).

125. Roussa, E. \& Krieglstein, K. GDNF promotes neuronal differentiation and dopaminergic development of mouse mesencephalic neurospheres. Neurosci. Lett. 361, 52-55 (2004).

126. Maden, M. Retinoid signalling in the development of the central nervous system. Nat. Rev. Neurosci. 3, 843-853 (2002).

127. Greco, S. J., Zhou, C., Ye, J.-H. \& Rameshwar, P. An Interdisciplinary Approach and Characterization of Neuronal Cells Transdifferentiated from Human Mesenchymal Stem Cells. Stem Cells Dev. 16, 811-826 (2007).

128. Reynolds, B. A., Tetzlaff, W. \& Weiss, S. A multipotent EGF-responsive striatal embryonic progenitor cell produces neurons and astrocytes. J. Neurosci. 12, 4565-74 (1992).

129. Louis, S. A. \& Reynolds, B. A. Generation and Differentiation of Neurospheres From Murine Embryonic Day 14 Central Nervous System Tissue. in Basic Cell Culture Protocols 265-280 (Humana Press, 2005). doi:10.1385/1-59259-838-2:265

130. Janesick, A., Wu, S. C. \& Blumberg, B. Retinoic acid signaling and neuronal differentiation. Cell. Mol. Life Sci. 72, 1559-1576 (2015).

131. Sanai, N. et al. Unique astrocyte ribbon in adult human brain contains neural stem cells but lacks chain migration. Nature 427, 740-744 (2004). 
132. Kozubenko, N. et al. Analysis of in vitro and in vivo characteristics of human embryonic stem cell-derived neural precursors. Cell Transplant. 19, 471-486 (2010).

133. Lepski, G., Jannes, C. E. \& Nikkhah, G. cAMP promotes differentiation of rodent neuronal progenitor cells. Stem Cell Stud. 1, 9 (2011).

134. Hogg, R. C., Chipperfield, H. \& Whyte, K. A. Functional maturation of isolated neural progenitor cells from the adult rat hippocampus. Eur. J. 19, 2410-2420 (2004).

135. Franzen, D. L. et al. Development and modulation of intrinsic membrane properties control the temporal precision of auditory brain stem neurons. J. Neurophysiol. 113, 524$536(2015)$.

136. Koester, J. \& Siegelbaum, S. A. Membrane Potential. Princ. Neural Sci. (2014).

137. Purves, D. \& Williams, S. M. (Stephen M. Neuroscience. (Sinauer Associates, 2001).

138. Ahlenius, H., Visan, V., Kokaia, M., Lindvall, O. \& Kokaia, Z. Neural stem and progenitor cells retain their potential for proliferation and differentiation into functional neurons despite lower number in aged brain. J. Neurosci. 29, 4408-19 (2009).

139. Koppensteiner, P., Boehm, S. \& Arancio, O. Electrophysiological profiles of induced neurons converted directly from adult human fibroblasts indicate incomplete neuronal conversion. Cell. Reprogram. 16, 439-46 (2014).

140. Johnson, M. A., Weick, J. P., Pearce, R. A. \& Zhang, S.-C. Functional Neural Development from Human Embryonic Stem Cells: Accelerated Synaptic Activity via Astrocyte Coculture. J. Neurosci. 27, 3069-3077 (2007).

141. Mothe, A. \& Tator, C. H. Isolation of Neural Stem/Progenitor Cells from the Periventricular Region of the Adult Rat and Human Spinal Cord. J. Vis. Exp. e52732 (2015). doi:10.3791/52732

142. Wright, S. H. Generation of resting membrane potential. Adv. Physiol. Educ. 28, 139-142 (2004).

143. Zaniboni, M., Cacciani, F. \& Groppi, M. Effect of input resistance voltage-dependency on DC estimate of membrane capacitance in cardiac myocytes. Biophys. J. 89, 2170-81 (2005).

144. Taylor, A. L. What we talk about when we talk about capacitance measured with the voltage-clamp step method. J. Comput. Neurosci. 32, 167-75 (2012).

145. Novikova, L. N., Novikov, L. N. \& Kellerth, J.-O. Biopolymers and biodegradable smart implants for tissue regeneration after spinal cord injury. Curr. Opin. Neurol. 16, 711-5 (2003).

146. Kleinman, H. K. \& Martin, G. R. Matrigel: Basement membrane matrix with biological activity. Semin. Cancer Biol. 15, 378-386 (2005).

147. Choi, N. Y. et al. A novel feeder-free culture system for expansion of mouse 
spermatogonial stem cells. Mol. Cells 37, 473-9 (2014).

148. Lee, S.-W. et al. Optimization of Matrigel-based culture for expansion of neural stem cells. Animal Cells Syst. (Seoul). 19, 175-180 (2015).

149. Prè, D. et al. A time course analysis of the electrophysiological properties of neurons differentiated from human induced Pluripotent Stem Cells (iPSCs). PLoS One 9, (2014).

150. Erceg, S. et al. Differentiation of human embryonic stem cells to regional specific neural precursors in chemically defined medium conditions. PLoS One 3, (2008).

151. Telias, M., Segal, M. \& Dalit, B.-Y. Electrical maturation of neurons derived from human embryonic stem cells. F1000 Res. 196, 1-10 (2014).

152. Anderson, G. W. et al. Characterisation of neurons derived from a cortical human neural stem cell line CTX0E16. Stem Cell Res. Ther. 6, 149 (2015).

153. Wei, D. et al. Cells of adult brain germinal zone have properties akin to hair cells and can be used to replace inner ear sensory cells after damage. Proc. Natl. Acad. Sci. 105, 2100021005 (2008).

154. Segal, R. A., Takahashi, H. \& McKay, R. D. Changes in neurotrophin responsiveness during the development of cerebellar granule neurons. Neuron 9, 1041-52 (1992).

155. Bez, A. et al. Neurosphere and neurosphere-forming cells: morphological and ultrastructural characterization. Brain Res. 993, 18-29 (2003).

156. Guo, X., Johe, K., Molnar, P., Davis, H. \& Hickman, J. Characterization of a human fetal spinal cord stem cell line, NSI-566RSC, and its induction to functional motoneurons. $J$. Tissue Eng. Regen. Med. 4, 181-93 (2010).

157. Jelitai, M., Anderová, M., Chvátal, A. \& Madarász, E. Electrophysiological characterization of neural stem/progenitor cells during in vitro differentiation: Study with an immortalized neuroectodermal cell line. J. Neurosci. Res. 85, 1606-1617 (2007).

158. Cho, T. et al. Human neural stem cells: Electrophysiological properties of voltage-gated ion channels. Neuroreport 13, 1447-1452 (2002).

159. Anderson, G. W. et al. Characterisation of neurons derived from a cortical human neural stem cell line CTX0E16. Stem Cell Res. Ther. 6, 149 (2015).

160. Labeed, F. H. et al. Biophysical characteristics reveal neural stem cell differentiation potential. PLoS One 6, 1-11 (2011).

161. Verpelli, C. et al. Comparative neuronal differentiation of self-renewing neural progenitor cell lines obtained from human induced pluripotent stem cells. Front. Cell. Neurosci. 7, 175 (2013).

162. Gao, B. X. \& Ziskind-Conhaim, L. Development of ionic currents underlying changes in action potential waveforms in rat spinal motoneurons. J. Neurophysiol. 80, 3047-3061 (1998). 
163. Oh, J. et al. Astrocyte-derived interleukin-6 promotes specific neuronal differentiation of neural progenitor cells from adult hippocampus. J. Neurosci. Res. 88, 2798-2809 (2010).

164. Jarvis, C. R. \& Andrew, R. D. Correlated electrophysiology and morphology of the ependyma in rat hypothalamus. J. Neurosci. 8, 3691-702 (1988).

165. Connors, B. Y. B. W. \& Ransom, B. R. CA 94305, U.S.A. (Received 24 June 1986). 1836, 287-306 (1987).

166. Zhong, S. et al. Electrophysiological behavior of neonatal astrocytes in hippocampal stratum radiatum. Mol. Brain 9, 1-16 (2016).

167. MacFarlane, S. N. \& Sontheimer, H. Electrophysiological changes that accompany reactive gliosis in vitro. J. Neurosci. 17, 7316-7329 (1997).

168. Bordey, A., Lyons, S. A., Hablitz, J. J. \& Sontheimer, H. Electrophysiological characteristics of reactive astrocytes in experimental cortical dysplasia. J. Neurophysiol. 85, 1719-31 (2001).

169. Adermark, L. \& Lovinger, D. M. Electrophysiological properties and gap junction coupling of striatal astrocytes. Neurochem. Int. 52, 1365-1372 (2008).

170. McKhann, G. M., D’Ambrosio, R. \& Janigro, D. Heterogeneity of astrocyte resting membrane potentials and intercellular coupling revealed by whole-cell and gramicidinperforated patch recordings from cultured neocortical and hippocampal slice astrocytes. $J$. Neurosci. 17, 6850-6863 (1997).

171. Burnard, D. M., Crichton, S. A. \& Macvicar, B. A. Electrophysiological properties of reactive glial cells in the kainate-lesioned hippocampal slice. 510, 43-52 (1990).

172. Mestre, A. L. G. et al. Extracellular Electrophysiological Measurements of Cooperative Signals in Astrocytes Populations. Front. Neural Circuits 11, 1-9 (2017).

173. Gunhanlar, N. et al. A simplified protocol for differentiation of electrophysiologically mature neuronal networks from human induced pluripotent stem cells. Mol. Psychiatry 23, 1336-1344 (2018).

174. Blanke, M. L. \& VanDongen, A. M. J. Activation Mechanisms of the NMDA Receptor. Biology of the NMDA Receptor (CRC Press/Taylor \& Francis, 2009).

175. Cull-Candy, S. G. \& Leszkiewicz, D. N. Role of Distinct NMDA Receptor Subtypes at Central Synapses. Sci. Signal. 2004, re16-re16 (2004).

176. Tovar, K. R. et al. Fast NMDA Receptor - Mediated Synaptic Currents in Neurons From Mice Lacking the $\varepsilon 2$ ( NR2B ) Subunit Fast NMDA Receptor - Mediated Synaptic Currents in Neurons From Mice Lacking the $\sqrt{ } 2$ ( NR2B ) Subunit. J Neurophysiol 83, 616-620 (2000).

177. Vicini, S. et al. Functional and pharmacological differences between recombinant Nmethyl-D-aspartate receptors. J. Neurophysiol. 79, 555-66 (1998). 
178. Joshi, I. \& Wang, L. Y. Developmental profiles of glutamate receptors and synaptic transmission at a single synapse in the mouse auditory brainstem. J. Physiol. 540, 861873 (2002).

179. Bardy, C. et al. Neuronal medium that supports basic synaptic functions and activity of human neurons in vitro. Proc. Natl. Acad. Sci. U. S. A. 112, E2725-34 (2015).

180. Hu, Y. et al. The telomerase inhibitor AZT enhances differentiation and prevents overgrowth of human pluripotent stem cell derived neural progenitors. J. Biol. Chem. jbc.M117.809889 (2018). doi:10.1074/jbc.M117.809889 